\title{
Silica in a Mars analog environment: Ka'u Desert, Kilauea Volcano, Hawaii
}

\author{
Kimberly D. Seelos, ${ }^{1}$ Raymond E. Arvidson, ${ }^{2}$ Bradley L. Jolliff, ${ }^{2}$ Steven M. Chemtob, ${ }^{3}$ \\ Richard V. Morris, ${ }^{4}$ Douglas W. Ming, ${ }^{4}$ and Gregg A. Swayze ${ }^{5}$ \\ Received 29 January 2009; revised 10 October 2009; accepted 19 October 2009; published 8 April 2010.
}

[1] Airborne Visible/Near-Infrared Imaging Spectrometer (AVIRIS) data acquired over the Ka'u Desert are atmospherically corrected to ground reflectance and used to identify the mineralogic components of relatively young basaltic materials, including 250-700 and 200-400 year old lava flows, 1971 and 1974 flows, ash deposits, and solfatara incrustations. To provide context, a geologic surface units map is constructed, verified with field observations, and supported by laboratory analyses. AVIRIS spectral endmembers are identified in the visible $(0.4$ to $1.2 \mu \mathrm{m})$ and short wave infrared $(2.0$ to $2.5 \mu \mathrm{m})$ wavelength ranges. Nearly all the spectral variability is controlled by the presence of ferrous and ferric iron in such minerals as pyroxene, olivine, hematite, goethite, and poorly crystalline iron oxides or glass. A broad, nearly ubiquitous absorption feature centered at $2.25 \mu \mathrm{m}$ is attributed to opaline (amorphous, hydrated) silica and is found to correlate spatially with mapped geologic surface units. Laboratory analyses show the silica to be consistently present as a deposited phase, including incrustations downwind from solfatara vents, cementing agent for ash duricrusts, and thin coatings on the youngest lava flow surfaces. A second, Ti-rich upper coating on young flows also influences spectral behavior. This study demonstrates that secondary silica is mobile in the Ka'u Desert on a variety of time scales and spatial domains. The investigation from remote, field, and laboratory perspectives also mimics exploration of Mars using orbital and landed missions, with important implications for spectral characterization of coated basalts and formation of opaline silica in arid, acidic alteration environments.

Citation: Seelos, K. D., R. E. Arvidson, B. L. Jolliff, S. M. Chemtob, R. V. Morris, D. W. Ming, and G. A. Swayze (2010), Silica in a Mars analog environment: Ka'u Desert, Kilauea Volcano, Hawaii, J. Geophys. Res., 115, E00D15, doi:10.1029/2009JE003347.

\section{Introduction}

[2] Analyses of remotely acquired spectral measurements are the primary means of passively identifying the composition of planetary surfaces. When specific minerals can be tied to a geologic or geomorphologic unit, important information about the original emplacement or formational environment, as well as geochemical conditions of subsequent alteration events, may also be inferred. Of interest to planetary scientists, particularly Mars researchers, are the types of minerals that record the influence of water, since waterrelated minerals and their host materials may indicate former

\footnotetext{
${ }^{1}$ Johns Hopkins University Applied Physics Laboratory, Laurel, Maryland, USA.

${ }^{2}$ Department of Earth and Planetary Sciences, Washington University in Saint Louis, Saint Louis, Missouri, USA.

${ }^{3}$ Department of Geological and Planetary Sciences, California Institute of Technology, Pasadena, California, USA.

${ }^{4}$ ARES, NASA Johnson Space Center, Houston, Texas, USA.

${ }^{5}$ U.S. Geological Survey, Denver, Colorado, USA.
}

Copyright 2010 by the American Geophysical Union. 0148-0227/10/2009JE003347 habitable zones. As an example, gray crystalline hematite identified by the Mars Global Surveyor (MGS) Thermal Emission Spectrometer (TES) in Meridiani Planum, Mars, [Christensen et al., 2000] was hypothesized to have formed in the presence of water after an integrated analysis of remote sensing data sets [Christensen et al., 2000; Hynek et al., 2002; Arvidson et al., 2003]. Because most known hematite on Earth is formed under aqueous conditions, the detection of hematite was a decisive factor in the selection of Meridiani Planum as a Mars Exploration Rover (MER) landing site. Subsequent surface measurements made by MER Opportunity confirmed a once vast water-rich environment [Squyres et al., 2004]. MER Spirit also uncovered distinctive mineralogy indicative of aqueous alteration on the opposite side of Mars in the Columbia Hills within Gusev crater. Minerals found there include silica and titanium-enriched phases in host rocks that exhibit volcanic and pyroclastic textures [Ming et al., 2006; Arvidson et al., 2008; Squyres et al., 2008]. Although these phases were not detected from orbit prior to landing, the discovery of silica enrichment is particularly intriguing because it should be the first and most 


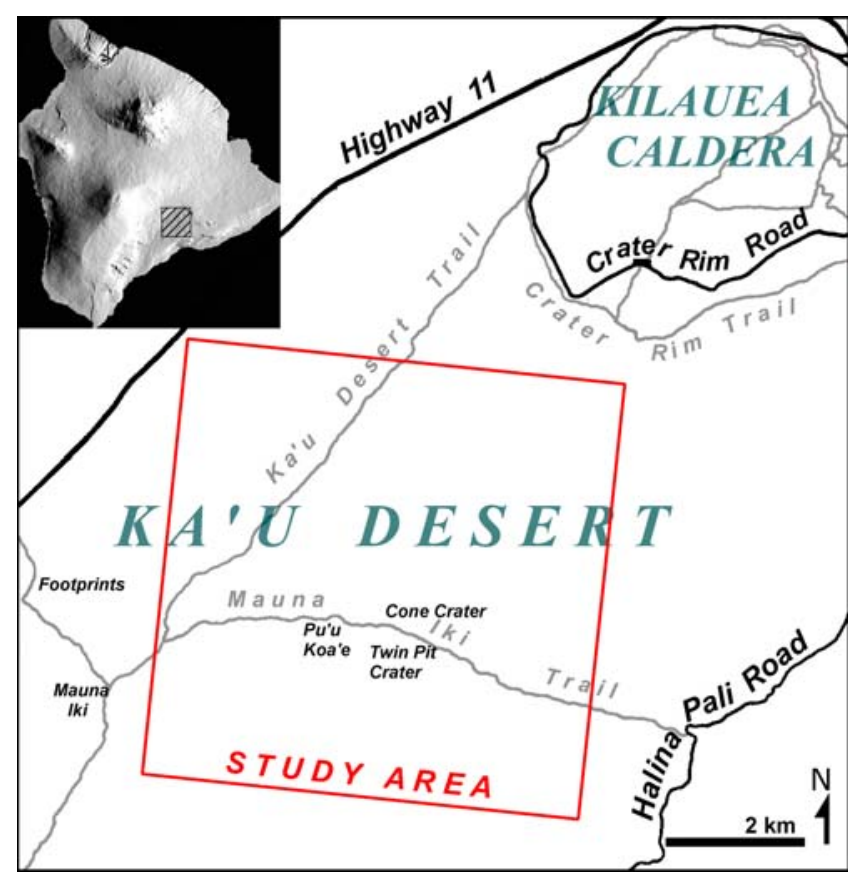

Figure 1. The Ka'u Desert study area located on the southwestern flank of Kilauea volcano on the big island of Hawaii (see shaded relief inset). The study area is outlined in red with roads (black), trails (gray), and regional landforms also labeled.

mobile constituent of aqueous alteration of basaltic materials under Martian conditions [McLennan, 2003].

[3] As more instruments are added to the Martian orbital repertoire, higher spatial and spectral sampling allow for increasingly detailed global, regional, and local context for in situ exploration. In the visible and near-infrared wavelength region ( $\sim 0.4$ to $5 \mu \mathrm{m})$, two hyperspectral reflectance spectrometers aid in this endeavor. The Mars Express (MEX) Observatoire pour la Minéralogíe, l'Eau, les Glaces et l'Activiteé (OMEGA) [Bibring et al., 2004] and the Mars Reconnaissance Orbiter (MRO) Compact Reconnaissance Imaging Spectrometer for Mars (CRISM) [Murchie et al., 2007] together provide global coverage of Mars at high spatial resolutions, from greater than $500 \mathrm{~m} /$ pixel for OMEGA at periapsis to $18 \mathrm{~m} /$ pixel in CRISM's highresolution targeted mode. Minerals that exhibit diagnostic absorption features in OMEGA and CRISM wavelength ranges are often diagnostic of specific environmental conditions in which crustal materials have interacted with water. Indeed, analyses of OMEGA and CRISM data have revealed a wide variety of sulfates, phyllosilicates, iron oxides, and opaline silica in discrete surface exposures on Mars [Arvidson et al., 2005; Gendrin et al., 2005; Poulet et al., 2005; Milliken et al., 2008; Bishop et al., 2009; McKeown et al., 2009; Weitz et al., 2010], implying that aqueous alteration processes were quite common in the Martian crust in past eras. Still, a majority of the surface of Mars remains dominated by basaltic spectral signatures [e.g., Bandfield et al., 2000; Bibring et al., 2005].

[4] The goal of this paper is to explore the Ka'u Desert, Hawaii, as a Mars analog terrain, using remote sensing data similar to that acquired by OMEGA and CRISM and to make in situ observations like those made by the instruments on board the MER rovers in order to understand the surface properties that govern the remotely observed spectral behavior. The Ka'u Desert provides an excellent Mars analog location with its young surface age $(<1000$ years), variety of altered as well as unaltered basaltic materials, relatively low amount of rainfall and vegetation, and active, acid sulfatedriven alteration processes. The analysis of Airborne Visible/ Near-Infrared Imaging Spectrometer (AVIRIS) data provides the remote spectral information for this study, while field observations and laboratory sample analyses yield spatial context and mineralogic detail, respectively.

\section{Ka'u Desert}

\subsection{Geography}

[5] The Ka'u Desert is located on the southwestern flank of the active Hawaiian shield volcano Kilauea on the big island of Hawaii (Figure 1). The barren landscape results from a combination of factors associated with its young surface age and leeward location relative to the volcano's summit and dominant northeasterly trade winds. Yearly precipitation ranges from $\sim 200 \mathrm{~cm}$ at the volcano's summit to $<100 \mathrm{~cm}$ in the lower reaches of the Ka'u Desert [Giambelluca and Sanderson, 1993]. The warm descending winds and high permeability of volcanic materials also lead to increased rates of evaporation and rainwater infiltration, respectively, resulting in a semiarid climate. Moreover, sulfur dioxide and other aerosols incorporated into the trade winds as they pass over Kilauea's active vents precipitate as acid rain [Siegel et al., 1990]. The net result is the Ka'u Desert: a parabolic-shaped, nearly vegetation-free zone extending downwind from Kilauea caldera.

[6] The area of focus for this study is centered at $19^{\circ} 30^{\prime} \mathrm{N}$ and $155^{\circ} 22^{\prime} 23^{\prime \prime} \mathrm{W}$, about $5 \mathrm{~km}$ southwest of Kilauea caldera at a mean elevation of $950 \mathrm{~m}$. The study site is approximately $6 \mathrm{~km}$ by $6 \mathrm{~km}$ aligned orthogonal to the AVIRIS observation. The site was chosen on the basis of preliminary examination of remote sensing data and previous work [Easton, 1987; Holcomb, 1987], which indicated the presence of a wide range of materials and volcanic landforms including lava flows of different types and ages, ash deposits, solfataras (fumarolic vents that emit steam and sulfurous gases), pit craters, and cinder cones. In order to minimize the spectral influence from vegetation, analyses were further limited to the area between the Ka'u Desert Trail to the northwest (parallel to the 1971 flow) and the fault scarp just southeast of the 1974 flow margin (see Figures 1 and 2).

\subsection{Geology}

[7] Five members of the Puna Basalt Formation, the youngest of three stratigraphic divisions for Hawaiian geology, are exposed within the study area [Easton, 1987]. In general, Puna Basalt is tholeiitic in composition, with a finegrained or glassy groundmass and olivine, plagioclase, and/or rare clinopyroxene phenocrysts [Wright, 1971]. The Observatory flows $(0.25-0.7 \mathrm{ka})$ constitute the oldest basalt in the study area and are thought to have originated from a long-term eruption of the Observatory vent near Kilauea's summit [Holcomb, 1987; Wolfe and Morris, 1996]. These widespread lava flows are dominantly pahoehoe, with ropey, hummocky surface textures. In contrast, the intermediate- 


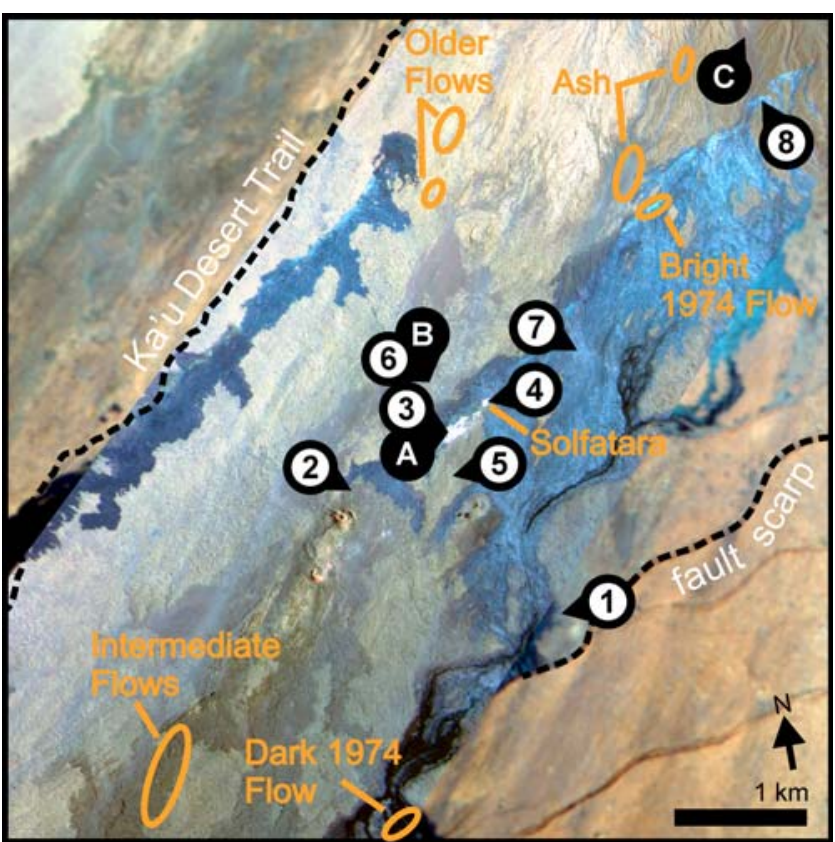

Figure 2. Sample collection, ground truth, and AVIRIS spectral end-member locations. Sample collection sites are numbered $1-8$, ground truth grid sites are labeled $\mathrm{A}-\mathrm{C}$, and AVIRIS spectral end-member locations are indicated in orange. The background is a mosaic of NS001 and AVIRIS data; both images are false color composites using $1.24,0.66$, and $0.48 \mu \mathrm{m}$ wavelengths as RGB, respectively. The study was focused between the Ka'u Desert trail to the northwest and the labeled fault scarp to the southeast.

aged (0.2-0.4 ka) Pu'u Koa'e flow is from an eruption of the Pu'u Koa'e cinder cone and consists of rough, blocky aa lavas. The Keanakako'i Ash Member is derived from several explosive eruptions of Kilauea that produced ash and lapilli as recently as 1924 . The most famous of these eruptions dates to 1790 when several Hawaiian warriors perished in what is believed to have been the base surge of that eruption [Swanson and Christensen, 1973]. The thickness of these layered ash deposits is greatest near the summit (about $10 \mathrm{~m}$ ) but varies widely downslope as a result of erosion and redeposition [Malin et al., 1983; Craddock et al., 2006]. The youngest lava flows in the study area originated from short-lived fissure eruptions along fractures of the Southwest Rift in 1971 and 1974. These flows are dominantly pahoehoe, although both transition to aa downslope.

\subsection{Weathering and Alteration}

[8] Many studies have examined the emplacement and weathering of Hawaiian basaltic lava flows through time. Very recent basalt flows exhibit the least evidence of weathering or alteration, consisting of primary mineralogy and/or a glassy cooling rind [White and Hochella, 1992]. Over time, physical breakdown of the delicate glassy surfaces of the lava flows allows development of coatings on the underlying vesicular rock. Coatings described by Farr and Adams [1984] consist of micrometer-scale laminations of silica and oxidized basaltic material, which lends the sur- faces a brownish to reddish coloration. The silica in these coatings is hypothesized to accrue through a combination of atmospheric deposition and leaching of locally derived detrital material on a time scale of 1000 years or more [Farr and Adams, 1984; Curtiss et al., 1985], suggesting that similar silica detritus coatings ought to be rare in the Ka'u Desert. Alternatively, silica coatings on several young Hawaiian flows, including Kilauean flows, have been hypothesized to form by leaching and/or dissolution and precipitation by meteoric water [Minitti et al., 2007]. The young age of the Ka'u Desert lava flows and the semiarid climate make it unlikely that complex sheet silicates (i.e., phyllosilicates) or well crystalline iron oxides would form, although these minerals are commonly observed as advanced weathering products of Hawaiian basalts under more humid conditions elsewhere on the islands [Sherman and Uehara, 1956].

[9] Formation rates of flow coatings and alteration minerals may be enhanced by acidic environmental conditions and an increased supply of detrital material. In the Ka'u Desert study area, the Keanakako'i Ash provides a ready supply of detrital material in the form of loose sand and ash, and is described by Malin et al. [1983] as scattered remnants and lag deposits in lava swales. Fluvial sands in transient stream channels [Craddock et al., 2006] and small accumulations of aeolian sands alongside positive topographic features indicate the mobilization and removal of the layered ash and tephra from preexisting pahoehoe lava flows. These stripped flows exhibit a yellowish-brown oxide coating inferred to be a result of interaction with the previously overlying tephra [Malin et al., 1983].

[10] Alteration of Keanakako'i Ash itself has been studied proximal to the summit of Kilauea and within the caldera. Schiffman et al. [2000] examined the distribution and mechanisms responsible for palagonitization, or the process by which the outer surfaces of glassy particles interact with pore fluids and devitrify to form fine-grained iron oxide and phyllosilicate rinds [Golden et al., 1993; Bishop et al., 1998; Schiffman et al., 2000]. Palagonitic tephra was observed only along certain sections of the circumferential fault system of the caldera and was presumed to be associated with former vent sites where hydrothermal activity had occurred. In contrast, ash and tephra in relatively arid and acidic areas were reported to exhibit nonpalagonitic weathering with a greater abundance of smectite and opaline silica, respectively [Sherman and Uehara, 1956; Schiffman et al., 2000]. Schiffman et al. [2006] also reported the formation of opaline silica and jarosite coatings immediately downwind from Kilauea caldera resulting from interaction with acidic fog.

[11] Solfataric activity at steam vents in the vicinity of the study area has also been previously documented by Casadevall and Hazlett [1983]. Mineral deposits related to the exhalation of hot steam and gases at Kilauea have been found to include elemental sulfur and sulfates (e.g., gypsum and anhydrite, thenardite, bloedite, and kieserite) and opaline silica (cristobalite and opal at high and low temperatures, respectively) [Naughton et al., 1976]. Advanced hydrothermal alteration on Mauna Kea has been found to produce clay minerals (e.g., montmorillonite, kaolinite, and saponite) and abundant iron oxides (e.g., hematite, goethite) [Swayze et al., 2003; Guinness et al., 2007; Hamilton et al., 2008]. The Mauna Kea minerals were also identified through visible and 
Table 1. Summary of Samples Collected From the Study Area, Laboratory Analyses Performed, and Mineralogic Inferences ${ }^{\mathrm{a}}$

\begin{tabular}{|c|c|c|c|c|c|c|}
\hline \multirow[b]{2}{*}{ Site } & \multirow[b]{2}{*}{ Sample } & \multirow[b]{2}{*}{ Field Description } & \multicolumn{3}{|c|}{ Laboratory Analyses } & \multirow[b]{2}{*}{ Mineralogic Inferences } \\
\hline & & & ASD & Raman & EM & \\
\hline 1 & HKD02-AH-10 & $\begin{array}{l}\text { Dark, loose, coarse grained ash; } \\
\text { aeolian ripples }\end{array}$ & $\mathrm{X}$ & $\mathrm{X}$ & & $\begin{array}{l}\text { Ferrous minerals (pyroxene, plagioclase), ferric minerals } \\
\text { (hematite) }\end{array}$ \\
\hline 2 & HKD02-MS-12 & Top surface crust of layered ash deposit & $\mathrm{X}$ & $\mathrm{X}$ & $\mathrm{X}$ & $\begin{array}{l}\text { Ferrous minerals (pyroxene, plagioclase), ferric minerals } \\
\text { (hematite, fibbroferrite), molecular } \\
\text { water, opaline silica coating }\end{array}$ \\
\hline 3 & HKD02-ST-18 & Lag deposit, southern solfatara & $\mathrm{X}$ & & & Ferrous-bearing minerals, molecular water, $\mathrm{Si}-\mathrm{OH}$ \\
\hline \multirow[t]{4}{*}{4} & HKD02-ST-05 & White surface crust, northern solfatara & $\mathrm{X}$ & $\mathrm{X}$ & & Molecular water, opaline silica \\
\hline & HKD02-ST-06 & Bright yellow sulfur, northern solfatara & $\mathrm{X}$ & & & Sulfur, molecular water \\
\hline & HKD02-ST-25 & Sulfurous crust at vent, northern solfatara & $\mathrm{X}$ & $\mathrm{X}$ & & Sulfur, ferric oxides, molecular water, $\mathrm{Si}-\mathrm{OH}$ \\
\hline & HKD02-ST-31 & Red oxidized basalt, northern solfatara & $\mathrm{X}$ & & & Ferric oxides (goethite), molecular water \\
\hline 5 & HKD02-ST-29 & Older basalt, near southern solfatara & $\mathrm{X}$ & $\mathrm{X}$ & & $\begin{array}{l}\text { Ferrous minerals (olivine, pyroxene, magnetite, plagioclase), } \\
\text { ferric minerals (hematite, fibbroferrite), opaline silica }\end{array}$ \\
\hline \multirow[t]{5}{*}{6} & HKD03-GR-06 & Older basalt, grayish & $\mathrm{X}$ & & & Ferrous- and ferric-bearing minerals, molecular water, $\mathrm{Si}-\mathrm{OH}$ \\
\hline & HKD03-GR-07 & Older basalt, reddish, thin brittle pieces & $\mathrm{X}$ & & & Ferrous- and ferric-bearing minerals, molecular water, $\mathrm{Si}-\mathrm{OH}$ \\
\hline & HKD03-GR-08 & $\begin{array}{l}\text { Brownish older basalt with small } \\
\text { white deposits }\end{array}$ & $\mathrm{X}$ & & & Ferrous- and ferric-bearing minerals, molecular water, $\mathrm{Si}-\mathrm{OH}$ \\
\hline & HKD03-GR-09 & Dark, loose, coarse grained ash & $\mathrm{X}$ & & & Ferrous-bearing minerals, minor molecular water, $\mathrm{Si}-\mathrm{OH}$ \\
\hline & HKD03-GR-17 & Case-hardened layer overlying layered ash & $\mathrm{X}$ & & & Ferrous-bearing minerals, molecular water, $\mathrm{Si}-\mathrm{OH}$ \\
\hline 7 & HKD02-74-03 & 1974 flow surface with white coating & $\mathrm{X}$ & $\mathrm{X}$ & $\mathrm{X}$ & Fe-, Ti-oxide and opaline silica coatings \\
\hline 8 & HKD03-EA-29 & 1974 flow spatter "pancakes" & $\mathrm{X}$ & & & Ferrous-bearing minerals or glass, molecular water, $\mathrm{Si}-\mathrm{OH}$ \\
\hline
\end{tabular}

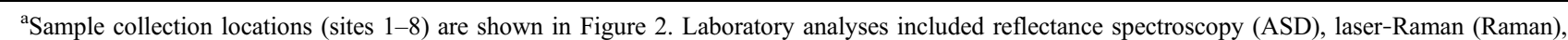
and electron microprobe (EM).

near infrared remote sensing and associated ground truth analyses similar to the methodology used here.

\section{Data Sets and Methodology}

\subsection{Remote Data}

[12] Remote sensing data sets, including those acquired by the AVIRIS instrument, the Landsat Thematic Mapper simulator (NS001), and an airborne panchromatic camera, were used for mineral identification and surface unit characterization. The AVIRIS instrument is carried by a NASA ER-2 aircraft and acquires hyperspectral image data from a nominal altitude of $20 \mathrm{~km}$. At this altitude, the pixel size is about $17 \mathrm{~m}$ on the ground with an $11 \mathrm{~km}$ imaging swath [Vane et al., 1993; Green et al., 1998]. The hyperspectral data set consists of 224 bands evenly distributed from 0.4 to $2.5 \mu \mathrm{m}$ with an average band width of $0.01 \mu \mathrm{m}$. Multispectral NS001 data consists of 8 bands distributed in the visible, short, and long wavelength infrared $(0.4-12 \mu \mathrm{m})$ spectral regions, from which red-green-blue (RGB) composite images were constructed. Spatial resolution of the NS001 and panchromatic camera data are $\sim 7 \mathrm{~m} /$ pixel and $\sim 2 \mathrm{~m} /$ pixel, respectively, allowing for detailed identification of unit boundaries and stratigraphic relationships. Both the panchromatic and NS001 images are part of a Kilauea volcanology data compilation [Glaze et al., 1992] and were obtained from the platform of a NASA C-130B aircraft at an altitude just over $3 \mathrm{~km}(10000 \mathrm{ft})$. Data were obtained in April of 1985 (NS001), October-November of 1988 (panchromatic), and April of 2000 (AVIRIS). No significant changes (e.g., new lava flows) were observed to occur during this time span.

[13] The wavelength range that AVIRIS samples is considered here in two segments: the visible and near infrared (VNIR) from 0.4 to $1.2 \mu \mathrm{m}$ and the short wave infrared (SWIR) from $\sim 2.0$ to $2.5 \mu \mathrm{m}$. The 1.2 to $2.0 \mu \mathrm{m}$ wavelength range contains large gaps resulting from saturated atmospheric absorptions and is largely disregarded (see Appendix A). The VNIR wavelength region records absorptions mainly caused by electronic transitions of the transition metal elements (primarily $\mathrm{Fe}^{2+}$ and $\mathrm{Fe}^{3+}$ in geologic materials), while SWIR absorptions are dominantly caused by overtones and/or combination tones of fundamental molecular vibrations [Pieters and Englert, 1993]. Molecular vibrations depend on specific mineral crystal structures, thus the vibrations of similar molecules in different minerals can produce features at different wavelength positions [e.g., Hunt et al., 1973]. However, the spectral characteristics of most rock-forming minerals have been identified through systematic laboratory work, and the most common minerals that exhibit diagnostic features in the SWIR (e.g., phyllosilicates, carbonates, hydroxides) are well documented. Some materials, such as pyroxenes and basaltic glass, may display absorption bands in both the VNIR and SWIR regions.

\subsection{Laboratory Data}

[14] Representative samples collected from the $\mathrm{Ka}$ 'u Desert were analyzed in the laboratory by reflectance spectroscopy, laser-Raman spectroscopy, and/or electron microprobe methods (Table 1). An Analytical Spectral Devices (ASD) reflectance spectrometer was used to acquire hyperspectral reflectance spectra in the wavelength range from 0.35 to $2.5 \mu \mathrm{m}$ for comparison to AVIRIS data. Radiance coefficient measurements are made in reference to a spectralon disk (as an approximation to a Lambertian surface) with incidence angle of zero degrees and emission angle of 12 degrees. The spot size of ASD laboratory measurements is $\sim 1 \mathrm{~cm}$. Resulting spectra were compared to reference spectra, namely the USGS library [Clark et al., 1993].

[15] Laser-Raman spectroscopy allows for nondestructive sampling of mineralogy on scales of $10 \mu \mathrm{m}$ or less. This technique is especially useful for analyzing delicate crusts or coatings that have a large degree of fine-scale variability. In a typical analysis, several traverses across a sample were 

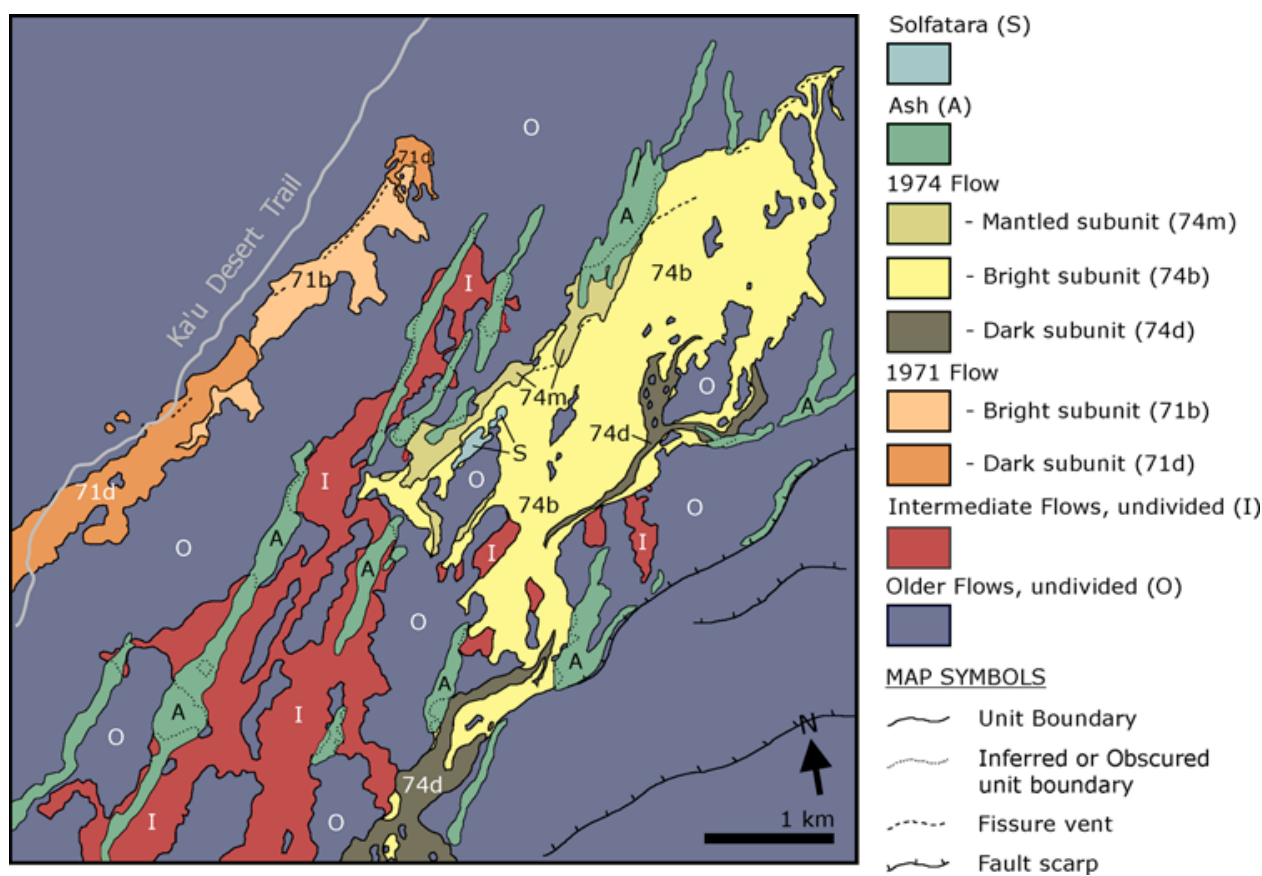

Figure 3. Geologic surface units map of the Ka'u Desert study area. Units identified include the older flows (O); intermediate flows (I); 1971 flow bright (71b) and dark (71d); 1974 flow bright (74b), dark (74d), and mantled (74m); ash (A); and solfatara (S).

performed, with measurements spanning the wave number range from 150 to $3600 \mathrm{~cm}^{-1}$. Obtained spectra were then compared to a database of Raman spectra [Kuebler et al., 2006] in order to identify specific mineral species. Samples that reveal particularly complex mineralogy or spatial variation by ASD or laser-Raman analyses were further analyzed with the electron microprobe (backscatter electron imaging) to characterize compositions across the surface and at depth. For several specimens with flat and smooth surfaces, we analyzed the surface with only carbon coating for preparation. For other samples, we used epoxy impregnation and made cross sections normal to coated surfaces. Electron microprobe results provide compositional variations on a micrometer scale.

\subsection{Methodology}

[16] The first step in our approach was to use results from previous work [Holcomb, 1987] in conjunction with a false color RGB composite generated from NS001 data (Figure 2), panchromatic data, and an RGB composite of AVIRIS data to define geologic surface units. Morphology, superposition and embayment relationships, and color patterns were examined. Field observations in the summers of 2002 and 2003, and subsequent laboratory analyses of collected samples were used to confirm or modify remotely inferred relationships among the units. Sample collection locations and descriptions are presented in Figure 2 and Table 1.

[17] AVIRIS data were then used to determine the spectral properties of the mapped geologic surface units and the study area as a whole. The three steps in reduction and analysis of AVIRIS hyperspectral data utilized in this study include (1) atmospheric correction and ground truth, (2) endmember selection and analysis, and (3) spatial reconstruction, including linear unmixing and band depth analysis. A detailed discussion of these techniques is provided in Appendix A. Used in concert, the field, laboratory, and remote sensing analysis techniques provide a complete view of Ka'u Desert materials analogous to what is obtained through orbital and robotic planetary exploration methods.

\section{Geologic Surface Units, Field Observations, and Mineralogic Characterization}

[18] Six morphologically distinguishable surface units were identified: (1) older flows, (2) intermediate flows, (3) 1971 flow, (4) 1974 flow, (5) ash, and (6) solfatara. The 1971 flow was further subdivided into bright and dark members, and the 1974 flow was subdivided into mantled, bright, and dark members (Figure 3 ). The descriptions below include remote and field observations followed by mineralogical insights gathered from laboratory ASD, laser-Raman, and electron microprobe analyses (Table 1).

\subsection{Older Flows and Intermediate Flows}

[19] The older flows unit is composed of observatory flows and other mainly pahoehoe flows older than $\sim 250$ years. In remote data sets, the older flows unit is widespread and forms the basal unit exposed in the study area. These flows exhibit high albedo compared with other units. Field observations reveal surfaces to be light gray to brownish in color and highly vesicular (Figure 4). Swales are commonly filled with the finely layered Keanakako'i Ash and its aeolian derivatives [Malin et al., 1983]. The areal coverage and thickness of the layered ash deposits increases with proximity to Kilauea caldera, eventually obscuring the older flows surface toward the northeast. The intermediate flows unit consists almost entirely of aa lavas located between the 1971 and 1974 flows that extend downslope to embay Pu'u 


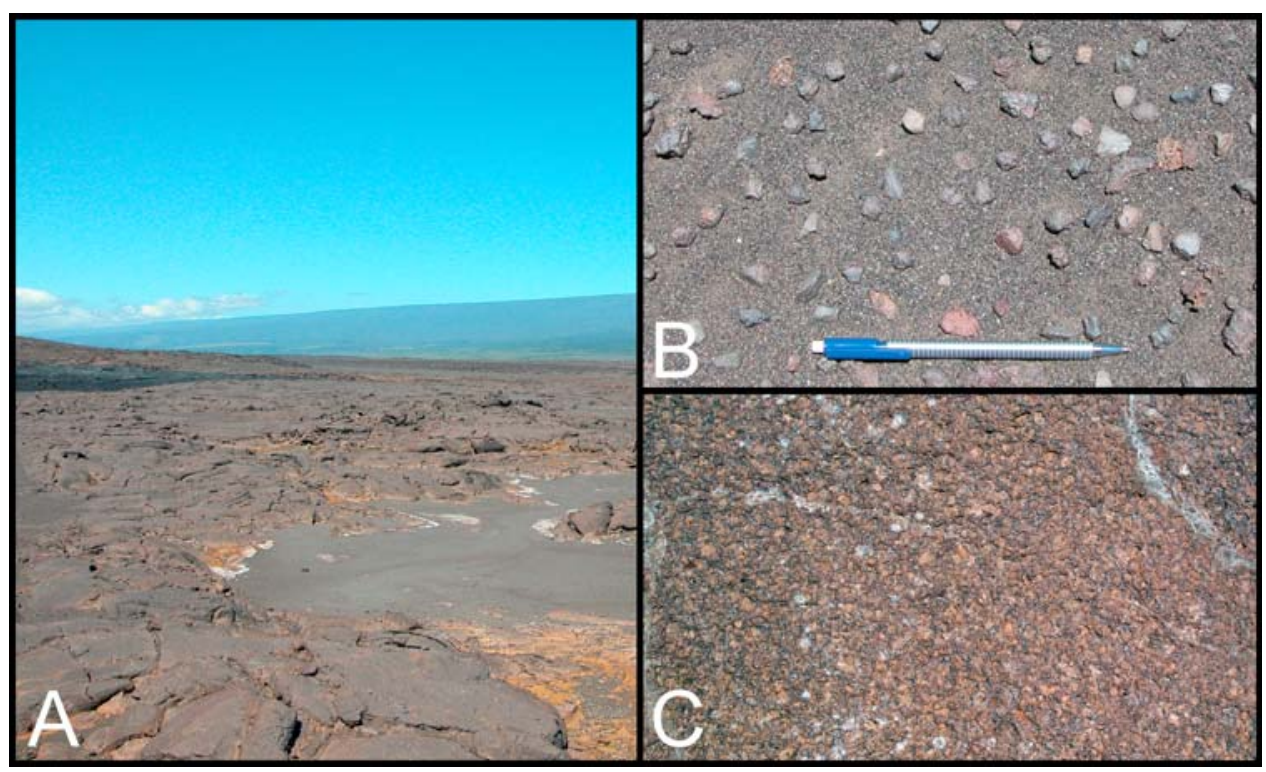

Figure 4. Field images of the older flows unit and superposed ash. (a) Typical older flows hummocky surface with small "puddles" of superposed finely layered ash (reddish-orange) and windblown ash (grayish). A lobe of the 1974 flow can be seen in the center left portion of the image. (b) Lag deposits of coarse ash and rounded basaltic pebbles are common in lava swales (pencil for scale). (c) Representative vesicular surface of the older flows unit; frame width is approximately $50 \mathrm{~cm}$.

Koa'e cinder cone. Previously identified flows associated with Pu'u Koa'e are included in this unit, as well as pahoehoe flow lobes of similar age that are discernible on the southeastern margin of the 1974 flow. The rough irregular surfaces of the aa lavas have led to the entrapment of aeolian ash, which has extensively mantled the upper portions of the flows and resulted in moderately higher albedo relative to unmantled aa flow surfaces downslope, such as those located in the wind shadow of Pu'u Koa'e.

[20] Samples of exposed older flows unit surfaces were collected at sites 5 and 6 (Figure 2 and Table 1). Reflectance spectra of these samples exhibit ferrous iron-related features with an absorption edge midpoint near $0.53 \mu \mathrm{m}$ and broad absorption feature centered at $0.98 \mu \mathrm{m}$ (Figure 5). Weak 1.4 and $1.9 \mu \mathrm{m}$ bands result from the presence of molecular water. The broad feature with an apparent center at $2.25 \mathrm{um}$ is interpreted to result from a combination of the $\mathrm{OH}$ stretch fundamental and an $\mathrm{Si}-\mathrm{OH}$ bend mode, which occurs at $2.20 \mathrm{um}$ in dehydrated opaline silica samples and at $2.26 \mathrm{um}$ when hydroxyls participate in hydrogen bonding with water molecules [Anderson and Wickersheim, 1964]. Although the $2.25 \mu \mathrm{m}$ feature could also be a result of overlapping absorptions due to metal-OH-bearing minerals (such as phyllosilicates), there is no evidence of this type of mineralogy from subsequent laser-Raman analyses.

[21] Laser-Raman spectra from sample HWKD02-ST29 reveal a mixture of primary mafic minerals (olivine, magnetite, pyroxene, and plagioclase) and secondary minerals (iron oxides and opaline silica) (Figure 6). Olivine exhibits a strong double peak at 824 and $857 \mathrm{~cm}^{-1}$ and magnetite has a major peak at $665 \mathrm{~cm}^{-1}$. The dominant Raman peaks for pyroxene occur at $319,386,666$, and $1014 \mathrm{~cm}^{-1}$ and those of plagioclase occur at 177,481 , and $514 \mathrm{~cm}^{-1}$. Ferric oxides identified include hematite $\left(\alpha-\mathrm{Fe}_{2} \mathrm{O}_{3}\right)$ with a prominent
Raman feature at $1314 \mathrm{~cm}^{-1}$, and fibroferrite $\left(\mathrm{Fe}^{3+}\left(\mathrm{SO}_{4}\right)(\mathrm{OH})\right.$. $5 \mathrm{H}_{2} \mathrm{O}$ ) with peak positions at 218, 427, 1006, 1094, and $3430 \mathrm{~cm}^{-1}$. The complexity of these spectra reflects a fine grained, poorly crystalline material over unaltered basaltic rock, which together with the presence of silica is consistent with the type of coating described by Farr and Adams [1984].

\subsection{The 1971 Flow and 1974 Flow}

[22] The 1971 and 1974 flows originate at multiple fissure vents aligned parallel to the Southwest Rift fracture system, beginning as pahoehoe and transitioning to aa downslope. The bright and dark members of the 1971 and 1974 flows correspond to the pahoehoe and aa flow surfaces, respec-

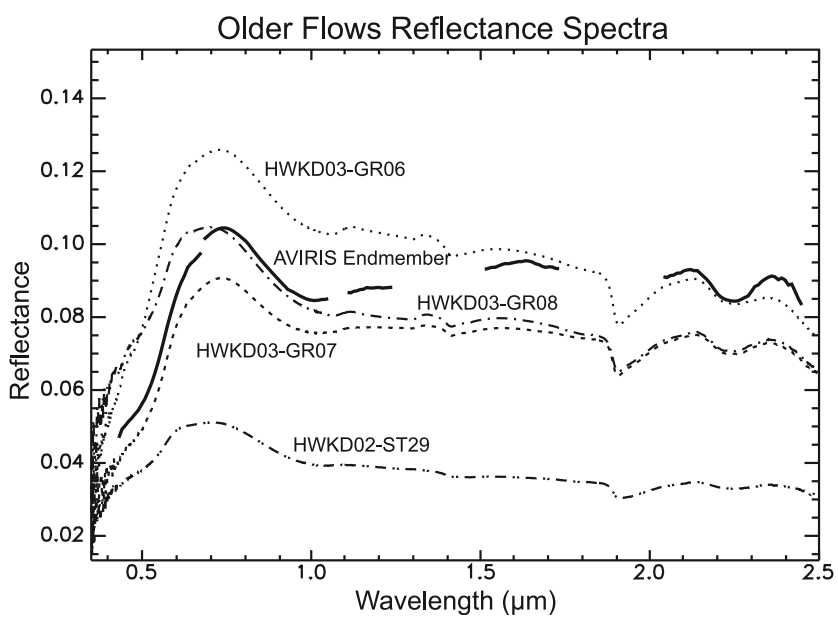

Figure 5. Laboratory reflectance spectra of collected older flows unit samples (patterned lines) along with the AVIRIS older flows end-member (solid line). 


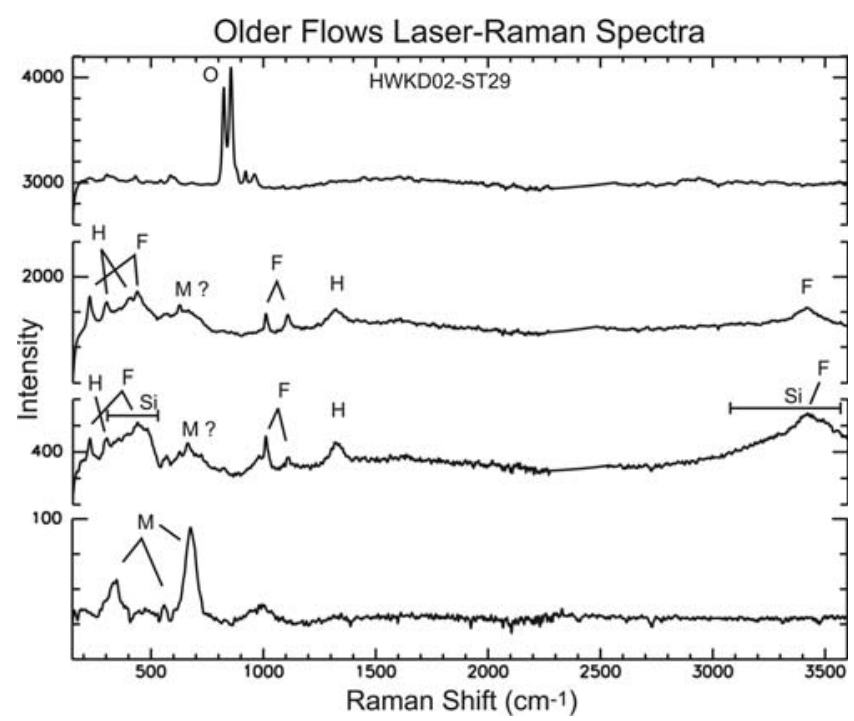

Figure 6. Raman spectra for a representative older flows sample, HWKD02-ST29. The uppermost spectrum is dominated by olivine $(\mathrm{O})$ whereas the middle two show evidence for hematite $(\mathrm{H})$, fibroferrite $(\mathrm{F})$, and opaline silica $(\mathrm{Si})$. Peaks in the lower spectrum are due to magnetite (M).

tively. In remote observations, the bright member exhibits a higher overall albedo as compared to the dark member. In field observations, pahoehoe surfaces of the bright member are observed to have thin discontinuous coatings with a whitish-blue opalescent appearance (Figure 7), causing the higher relative albedo compared to uncoated aa surfaces (dark member). The pahoehoe coatings are thickest on the spatter ramparts surrounding source fissure vents, becoming less pronounced downflow. Bright coatings are not observed on exposed contraction cracks, aa lava surfaces, or in places where the original glassy pahoehoe surface has been removed by weathering processes [Chemtob et al., 2006; Chemtob et al., 2009]. The mantled member of the 1974 flow is an example of the latter case, where mantling by windblown ash grains on the leeward, upslope portions of the 1974 flow has not only darkened the flow surface but partially mechanically eroded the bright surface coating through saltation.

[23] Because of the similarity between the 1971 and 1974 flows, samples were acquired only from the more easily accessible 1974 flow. Samples representative of the bright member of the 1974 flow include HWKD03-EA29, a thickly coated spatter "pancake" acquired adjacent to a remnant fissure vent at site 8 (Figure 2 and Table 1), and HWKD027403 , an example of the more typical flow surface located downflow from the source vent where patches of bright coating appears thinner and discontinuous (site 7). The ASD reflectance spectrum for HWKD02-7403 exhibits a negative slope toward longer wavelengths whereas the coated spatter sample does not (Figure 8). The change in observed spectral slope may be related to thickness of the coating; at longer wavelengths the coating is optically thin and allows greater absorption by the underlying dark basalt, thereby producing the negative infrared slope. Absorption features in these spectra include an absorption edge near $0.4 \mu \mathrm{m}$ and broad $1.0 \mu \mathrm{m}$ band due to ferrous iron. Subtle absorptions at 1.4 and $1.9 \mu \mathrm{m}$ hint at the presence of molecular water in the HWKD03-EA29 sample, and the feature at $2.25 \mu \mathrm{m}$ suggests opaline silica.

[24] Laser-Raman spectral analysis of the coated surface of sample HWKD02-7403 show distinct Raman peaks most similar to the reference spectrum of anatase $\left(\mathrm{TiO}_{2}\right)$ (Figure 9) along with amorphous opaline silica. Additional Fe-Ti oxides have been described by Chemtob et al. [2009]. Further examination of this sample with the electron microprobe

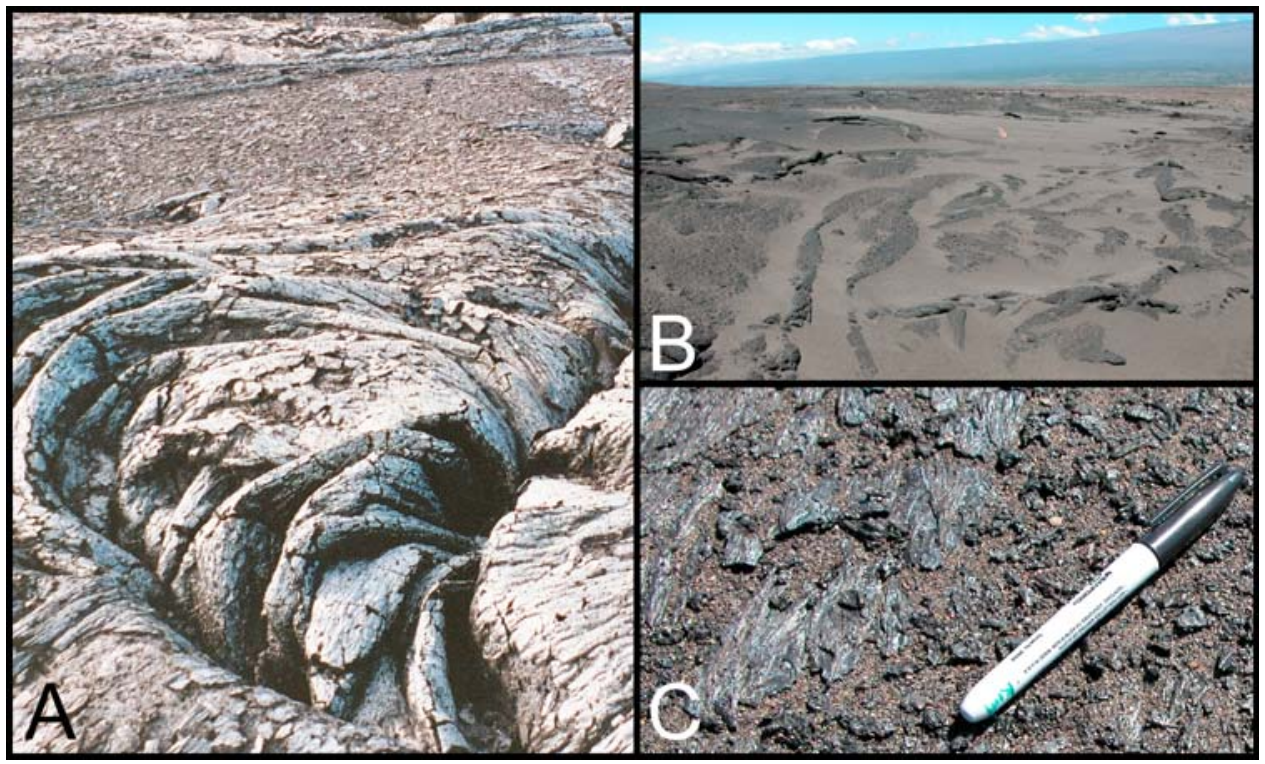

Figure 7. Field images of the 1974 flow. (a) Whitish-blue surface coatings are commonly observed on this ropey, pahoehoe lava flow. (b) The windward margin (foreground) is partially covered by aeolian ash and distinguished as the mantled subunit of the 1974 flow. (c) Saltation of ash grains in the mantled subunit may be responsible for abrasion and removal the bright surface coating (pen for scale). 


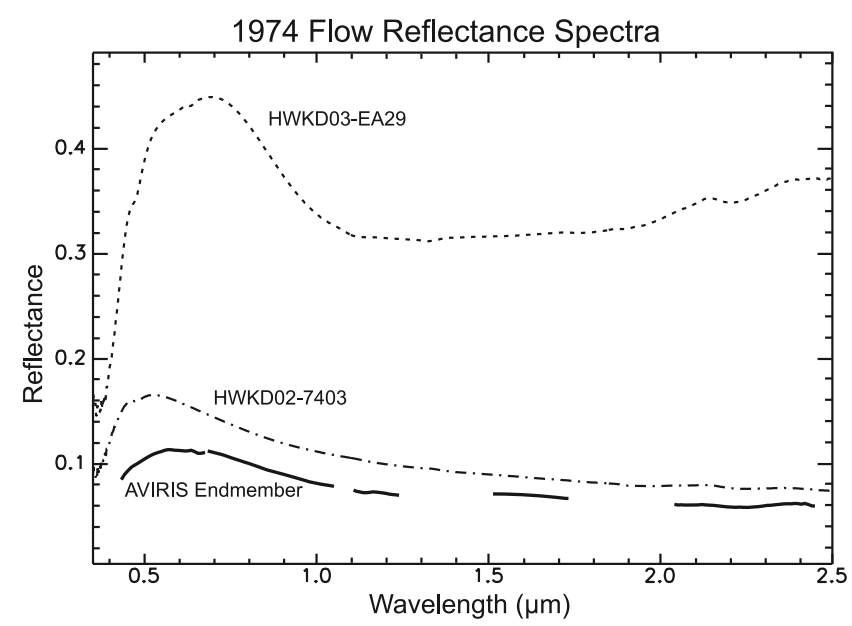

Figure 8. Laboratory reflectance spectra of 1974 flow samples HWKD03-EA29 and HWKD02-7403 (patterned lines) along with the bright 1974 flow AVIRIS end-member (solid line).

revealed that the uppermost surface of the 1974 flow consists of a discontinuous, soft (easily scratched with a pencil or fingernail) substance that displays a 5-10 $\mu \mathrm{m}$-scale polygonal texture (Figure 10). In cross section, the bright coating is a thin $(\sim 2-5 \mu \mathrm{m})$ layer enriched in $\mathrm{Ti}$ and $\mathrm{Fe}$ that overlies $\mathrm{a} \sim 10-15 \mu \mathrm{m}$ colorless silica-rich layer [see also Minitti et al., 2007; Chemtob et al., 2009]. The softness of the upper coating may explain the ease of its removal by abrasion of saltating ash grains within the mantled member of the 1974 flow; the silica-enriched layer was undisturbed by similar laboratory attempts to remove it.

[25] Observations of bright coatings only on the original glassy surfaces of the 1971 and 1974 pahoehoe flows, increasing in occurrence near source vents, and absence on exposed thermal contraction cracks suggest that bright coating formation is contemporaneous with flow emplacement. It may be related to degassing from the flow as it cools and reacts with the environment [White and Hochella, 1992], or perhaps deposition from hot vent fluids that accompanied

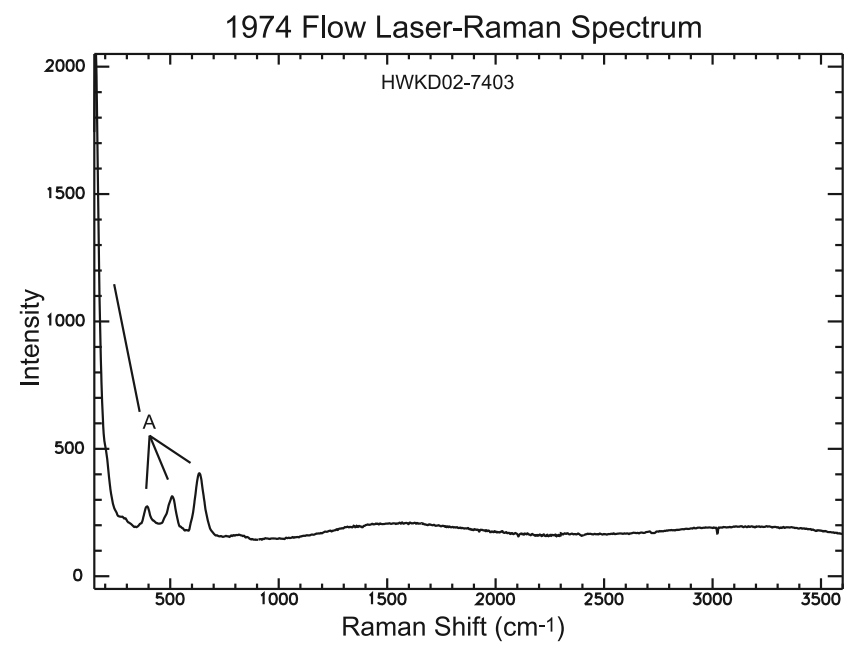

Figure 9. Raman spectrum of the 1974 flow sample HWKD02-7403. Dominant peaks are due to anatase (A).
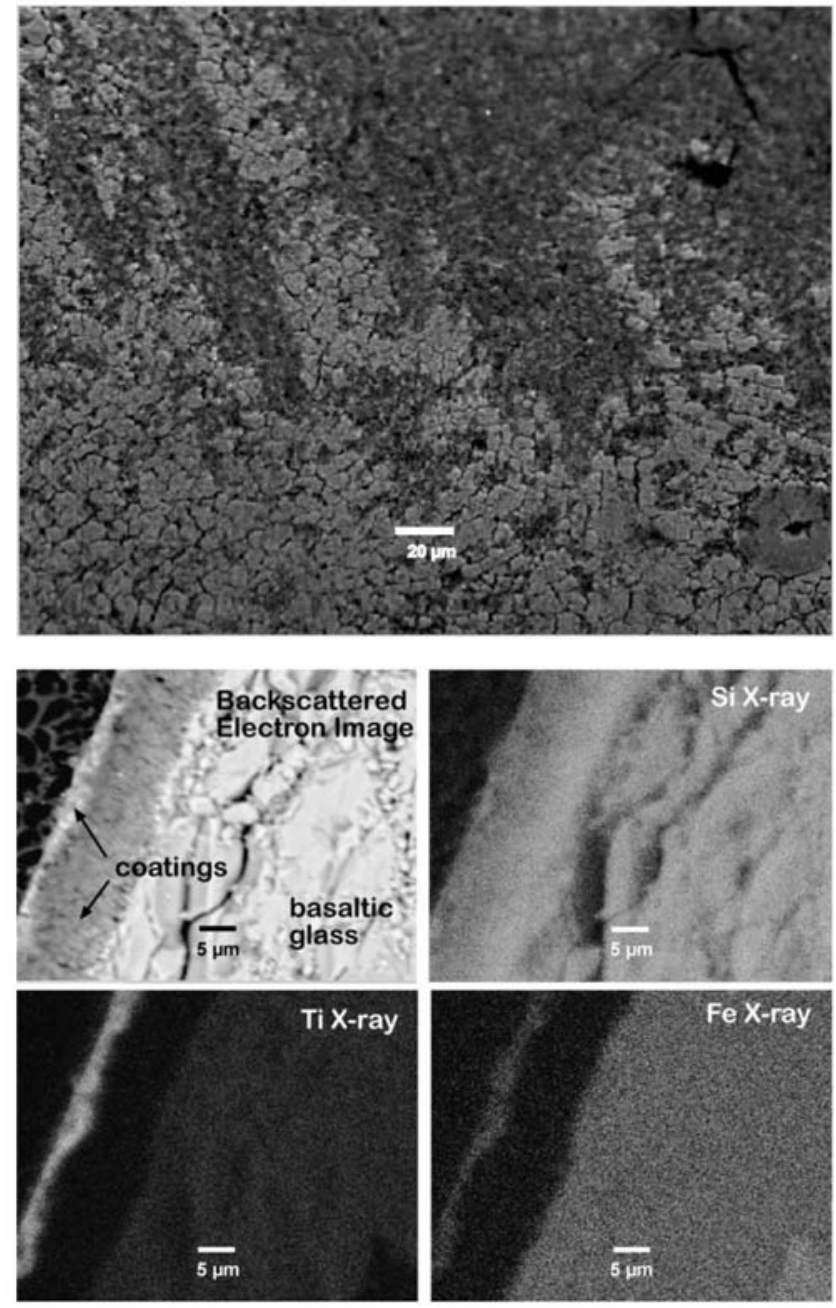

Figure 10. Electron microprobe images of the coated 1974 flow sample HWKD02-7403. (top) The backscattered electron image of the unprepared (aside from carbon coating) surface shows discontinuous areas of a relatively bright (high Z), polygonal-textured substance. (bottom) X-ray profile images reveal the vertical structure and composition of the coatings. A thin $(2-5 \mu \mathrm{m}) \mathrm{Ti}-$ and Fe-enriched coating overlies a slightly thicker $(\sim 10 \mu \mathrm{m})$ Si-rich layer. Note the sharp contact between the basalt substrate and silica-rich coating in the Fe X-ray image.

the eruption. The low solubility of titanium oxide under typical surface conditions would preserve the coating for some time, although it appears susceptible to mechanical weathering agents. In more humid environments, the iron component of the coating may readily oxidize and help to break down the coating at a higher rate than in the Ka' $\mathrm{u}$ Desert. A more detailed analysis of these coatings can be found in Chemtob et al. [2009]; Minitti et al. [2007] also examined the chemical and spectral characteristics of similar coatings from nearby Kilauea summit, Mauna Iki, and Mauna Ulu.

\subsection{Ash}

[26] The ash unit consists mainly of deposits of the reworked sand-sized grains of Keanakako'i Ash. In the remote 


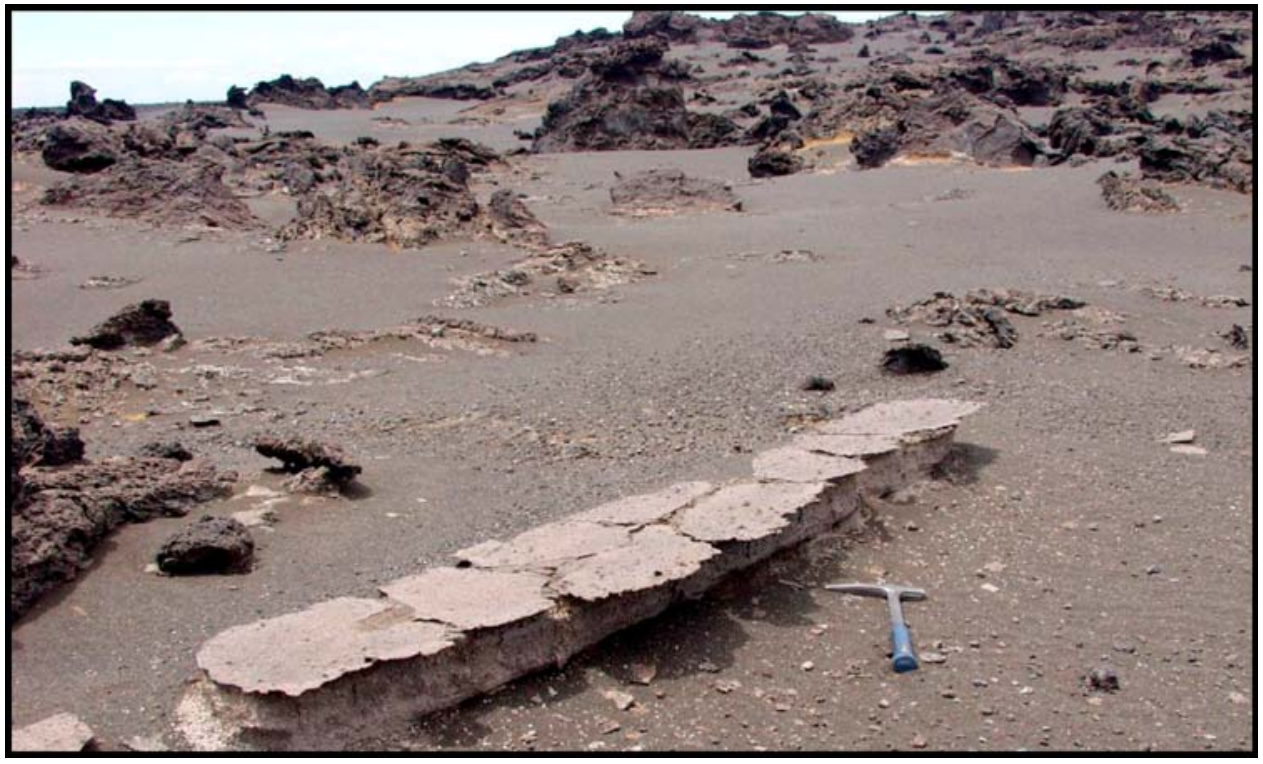

Figure 11. Field image of layered ash crusts and windblown ash adjacent to Pu'u Kao'e cinder cone. The rough texture of aa lavas that make up the intermediate flows unit (background) also serves to capture windblown ash, which has a uniform gray appearance in this image. On the scale of an AVIRIS pixel, outcrops of the layered ash and crusts (foreground) are indistinguishable and dominated spatially by the aeolian-type deposits. Thus, both the aeolian and layered ash constitute the mapped ash geologic surface unit. This location is the sampling site for HWKD02-MS12.

data sets, these deposits are characterized by semicircular to elongated patches typically oriented parallel to northeasterly trade winds, and with near uniform albedo that are spatially coherent at AVIRIS resolution. In the field, examination of ash grains reveals that they are typically $1-2 \mathrm{~mm}$ in diameter, subangular to subrounded, and fairly well sorted but stratified such that larger grains form a thin lag deposit over finer-grained particles. Accumulations in lava flow swales, in ripples and duneforms against topographic barriers, and within local low areas on rough aa lavas are common (Figure 11). These observations are consistent with the description of aeolian ash given by Malin et al. [1983].

[27] Also included as part of the ash unit are in-place deposits of layered Keanakako'i Ash. Contiguous deposits tend to be limited to the upper reaches of the Ka'u Desert outside of the study area, but small (submeter scale) patches of finely layered ash and lapilli are evident in the lower portions of the study area as well. Generally, these small outcrops are significantly mantled by the reworked sands described above, and are thus not mapped as a separate unit. However, the uppermost surface of this layered ash is sometimes exposed as a thin, lightly indurated crust, and likely contributes to the ash unit's overall spectral signature.

[28] Representative samples of both the surface crusts and loose aeolian ash were collected at sites 2 and 6 for laboratory analysis (Figure 2 and Table 1). ASD reflectance spectra of sampled ash crusts (HWKD03-GR17, HWKD02MS12) are noticeably brighter than those of the aeolian ash samples (HWKD02-AH10, HWKD03-GR09) (Figure 12). In both crust and aeolian ash samples, absorption bands in the VNIR range include a weak $0.52 \mu \mathrm{m}$ absorption edge (midpoint) and broad absorption feature centered just short of $1.0 \mu \mathrm{m}$. These features indicate $\mathrm{Fe}^{2+}$ in basaltic glass and/or pyroxene, perhaps with minor contributions of poorly crystalline iron oxides. The 1.4 and $1.9 \mu \mathrm{m}$ water bands are more clearly expressed in the ash crust spectra than in the aeolian ash, as is the $2.25 \mu \mathrm{m}$ absorption considered to result from opaline silica.

[29] Laser-Raman and electron microprobe analyses corroborate the mineralogic interpretations based on the sample

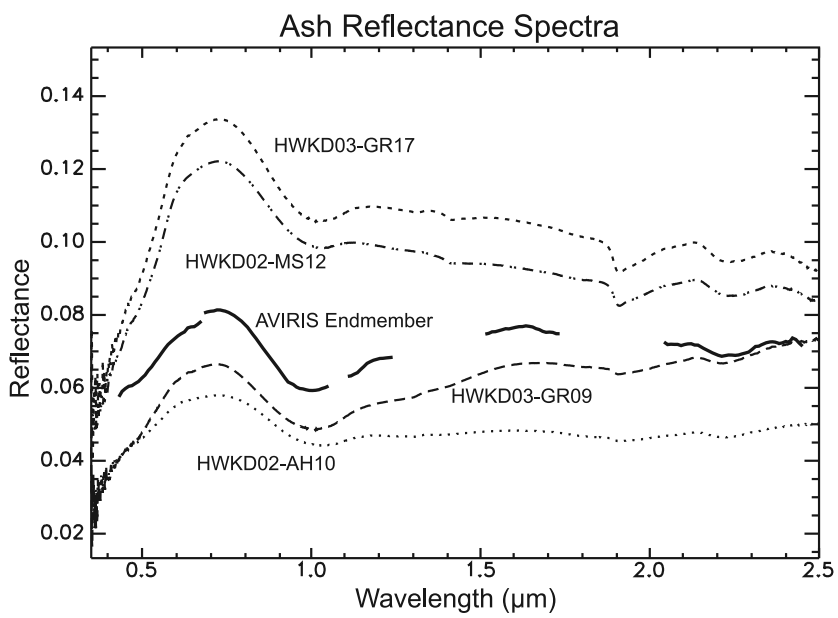

Figure 12. Laboratory reflectance spectra of ash samples (patterned lines) along with the ash AVIRIS end-member (solid line). Upper two sample spectra (HWKD03-GR17 and HWKD02-MS12) are from layered ash surface crusts (Figure 11) while the lower two (HWKD03-GR09 and HWKD02-AH10) are from loose aeolian ash deposits. The AVIRIS end-member spectrum appears to represent a spectral average of the spatially coexistent ash types. 


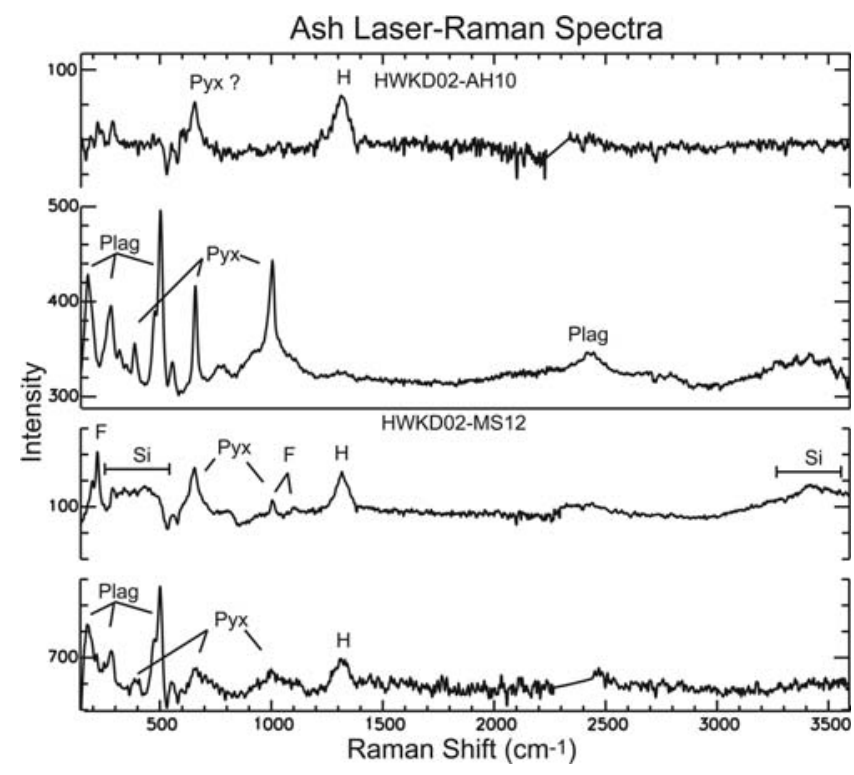

Figure 13. Raman spectra of ash samples (top) HWKD02AH10 and (bottom) HWKD02-MS12. Peaks diagnostic of plagioclase (Plag), pyroxene (Pyx), and hematite $(\mathrm{H})$ were identified in both samples. Opaline silica (Si) was predominantly found in the ash crust sample (HWKD02-MS12), along with a weak indication of fibroferrite $(\mathrm{F})$.

reflectance spectra. Loose aeolian ash (HWKD02-AH10) contains predominantly primary silicate minerals (pyroxene and plagioclase) whereas the ash crust (HWKD02-MS12) exhibits hematite, fibroferrite, and opaline silica in addition to these minerals (Figure 13). The indication of hematite may be compromised, however, by effects induced by the laser-Raman; it is possible that poorly crystalline ferric oxides such as fibroferrite, ferrihydrite, or perhaps goethite were heated and recrystallized to hematite by the laser beam during measurement.

[30] To further characterize the nature of the ash crusts, Figure 14 shows a false color backscattered electron image of a cross section of sample HWKD02-MS12. Individual ash grains appear finely crystalline, and surrounded by a $10-30 \mu \mathrm{m}$ layer of amorphous silica. The silica is preferentially located on the top surfaces of the grains, and boundaries between ash grains and silica are distinct. While this may be an indication that the silica was derived externally through dissolution and subsequent precipitation as the coating and cementing agent [Minitti et al., 2007], note that the lack of chemical gradient between a basaltic surface (the ash grains) and coating does not necessarily rule out direct leaching as the responsible mechanism.

\subsection{Solfatara}

[31] The youngest unit mapped is that of the solfatara. Distinguished remotely by its bright appearance, this unit consists of active steam and sulfurous vents (Figure 15a) along a fracture system that parallels the margin of the 1974 flow and extends into the adjacent older flows unit. Bright white and yellow incrustations surround the vents, and are preferentially located in the downwind direction relative to vent openings (Figure 15b). Elemental, crystalline sulfur and other mineral accumulations are observed in abundance in near surface cavities in the host basalt flows, but little else is observed on the surface other than the white and yellowish incrustations. The basaltic host rock within the solfatara unit appears reddish in coloration, a visual indication of alteration (oxidation) by steam and other hot gaseous components. Local deposits of windblown ash and pebble lag deposits are also found within the unit.

[32] A diverse collection of samples from the solfatara unit includes the white and yellow surface incrustations, windblown ash and lag deposits, and altered host rock (Table 1). In ASD reflectance spectra (Figure 16), a dramatic absorption edge that occurs at $0.45 \mu \mathrm{m}$ in samples HWKD02-ST06 and HWKD02-ST25 is the intrinsic absorption of native sulfur. These two samples also have significant amounts of water, indicated by absorptions at 0.96 , $1.15,1.4$, and $1.9 \mu \mathrm{m}$, in addition to opaline silica at $2.25 \mu \mathrm{m}$ in HWKD02-ST25. The presence of an $\mathrm{Fe}^{3+}$-bearing phase is strongly indicated for sample HWKD02-ST31 (a reddish altered basalt), and less so in HWKD02-ST25, by the presence of the strong absorption near $0.51 \mu \mathrm{m}$ and the minimum centered near $0.9 \mu \mathrm{m}$. The spectrum is consistent with that of poorly crystalline goethite $(\alpha-\mathrm{FeOOH})$ [Morris et al., 1985]. Sample HWKD02-ST18, a lag deposit with ash and fragments of nearby incrustations, has a weak 0.9 to $1 \mu \mathrm{m}$ band, implying more prominent contribution of ferrous minerals. Sample HWKD02-ST05 does not show particularly strong spectral evidence for any iron-bearing phase, instead it shows strong molecular water absorptions and the opaline silica absorption at $2.25 \mu \mathrm{m}$. Indeed, most solfatara sample spectra exhibit molecular water features and the $2.25 \mu \mathrm{m}$ absorption resulting from opaline silica. The only sample which does not exhibit strong opaline silica absorptions is HWKD02-ST06, a bright yellow incrustation that is dominated by native sulfur.

[33] To verify the interpretations based on ASD reflectance spectra, the predominant yellowish and whitish incrustations (HWKD02-ST2, HWKD02-ST05) were examined using the

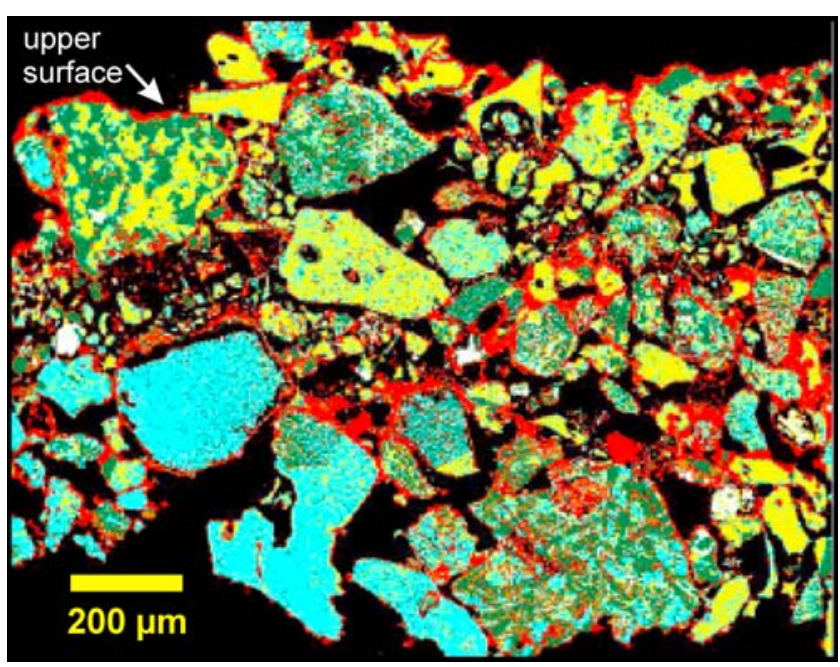

Figure 14. Cross section of ash crust sample HWKD02MS12 shown in false color backscattered electron image. Ash grains (multicolor) are cemented by finer-grained particulates and 10-30 $\mu \mathrm{m}$ accumulations of silica (red), preferentially located on the tops of the grains. 


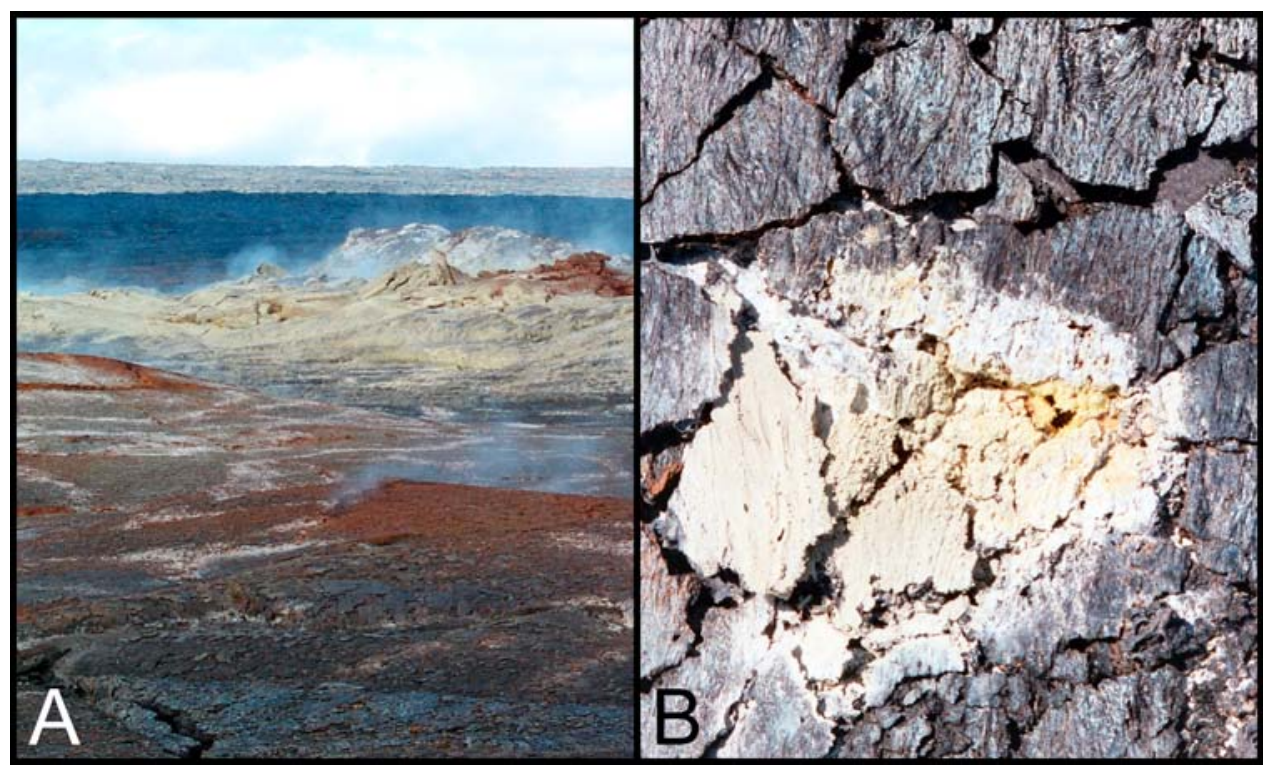

Figure 15. Field images of the solfatara unit. (a) Bright white and yellow surface incrustations, reddish altered basalt of the 1974 flow, and white vein-filling materials comprise the dominant surface types. (b) Close-up of small vent within the 1974 flow host rock that shows crystalline sulfur at the vent opening (bright yellow right of center) and a white incrustation being deposited preferentially in the downwind direction (toward the left). Image width is approximately $30 \mathrm{~cm}$.

laser-Raman. Samples HWKD02-ST2 and HWKD02-ST05 show well-defined peaks at 220 and $473 \mathrm{~cm}^{-1}$ owing to crystalline native sulfur and very broad peaks at 475 and $3450 \mathrm{~cm}^{-1}$ owing to opaline silica, respectively (Figure 17).

\section{AVIRIS-Based Spectral Characterization}

\subsection{End-Member Selection and Interpretation}

[34] Six spectral end-members were identified within the AVIRIS scene and labeled according to their location with

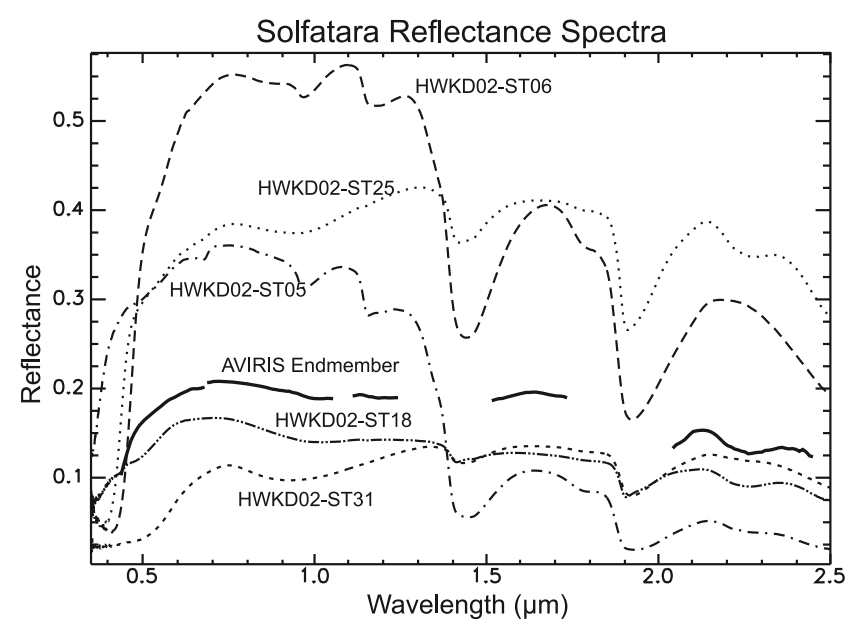

Figure 16. Laboratory reflectance spectra of solfatara samples (patterned lines) along with the solfatara AVIRIS endmember (solid line). The spectral diversity is reflective of the variety of materials found within the relatively small areal extent of the solfatara unit. The AVIRIS end-member spectrum indicates subpixel mixing between the different materials. respect to the geologic surface units map (Figures 2 and 3): (1) older flows, (2) intermediate flows, (3) ash, (4) bright 1974 flow, (5) dark 1974 flow, and (6) solfatara. The older flows spectral end-member location corresponds to a relatively bright region of the older flows geologic unit, located just upslope from the 1971 flow. The intermediate flow endmember originates from an area on the southwest portion of the flow where there appears to be minimal mantling of aeolian ash. The ash end-member pixels correspond to a large ash deposit upslope from the margin of the 1974 flow. Bright and dark end-member pixels for the 1974 flow are

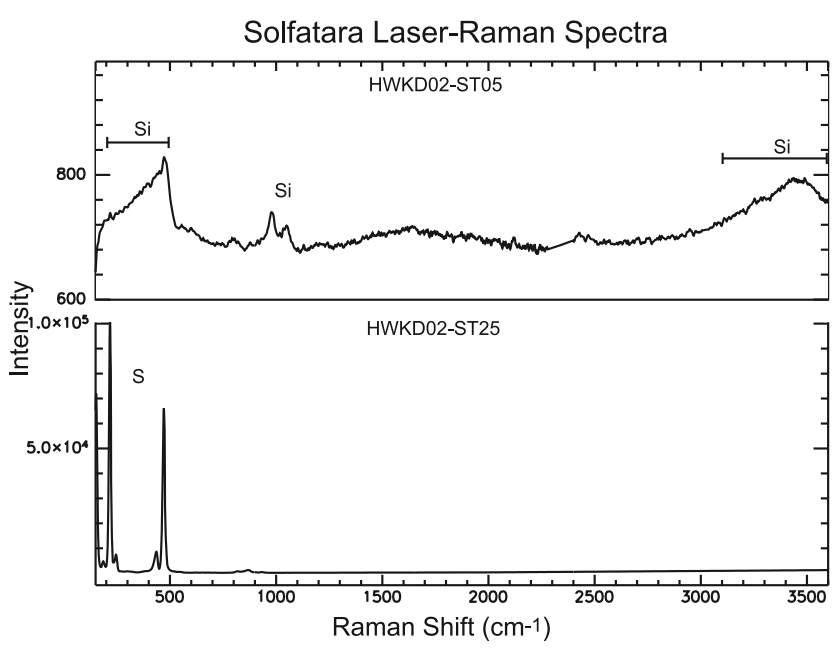

Figure 17. Raman spectra of commonly observed surface crusts at the solfatara, samples (top) HWKD02-ST05 and (bottom) HWKD02-ST25. Native sulfur (S) and opaline silica $(\mathrm{Si})$ are the dominant minerals identified in the yellow and white surface crusts, respectively. 


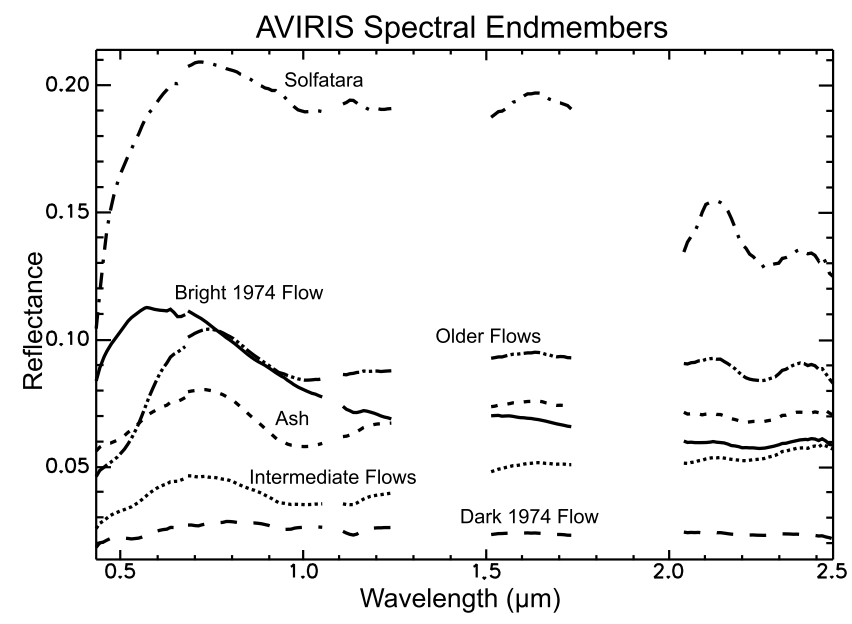

Figure 18. AVIRIS end-members identified in the $\mathrm{Ka}$ 'u Desert through hyperspectral analysis procedures (Appendix A). End-members for which representative samples were collected are also plotted alongside sample reflectance spectra in Figures 5, 8, 12, and 16.

situated along the heavily coated spatter rampart of a fissure vent and on the dark aa lavas of the 1974 flow, respectively. The solfatara end-member pixel corresponds spatially to the brightest area of the solfatara unit, pictured in Figure 15a.

[35] The older flows AVIRIS end-member exhibits overall reflectance values intermediate to those of the samples collected from the older flows unit (Figure 18). A prominent opaline silica absorption is evident at $2.25 \mu \mathrm{m}$, a ferric absorption edge is centered at $0.58 \mu \mathrm{m}$, and a broad absorption feature occurs near $1.0 \mu \mathrm{m}$, which probably results from the presence of both $\mathrm{Fe}^{2+}$ and $\mathrm{Fe}^{3+}$. On the basis of laboratory results and previous studies [e.g., Morris et al., 1985], these features imply the presence of finely crystalline primary mafic minerals in addition to secondary minerals (e.g., hematite, fibroferrite, and silica) that have accreted over time in the form of a surface coating [Farr and Adams, 1984], possibly with contribution from altered remnants of overlying layered ash deposits. The intermediate flows AVIRIS end-member is similar to that of the older flows, but exhibits lower overall reflectance and a slightly positive slope at longer wavelengths. Although subdued, VNIR absorption features in the intermediate flows spectrum are representative of the same mineralogic types as those inferred for the older flows end-member.

[36] With a visible peak near $0.55 \mu \mathrm{m}$ and a negative slope into the infrared, the bright 1974 flow AVIRIS endmember is consistent with laboratory reflectance spectra of 1974 flow samples that exhibit the bright surface coating (Figure 8) [see also Bishop et al., 2003; Minitti et al., 2007]. The end-member spectrum is darker in overall reflectance values as compared to the sample spectra, perhaps alluding to the high spatial variability in coating thickness, which drives albedo, as well as a collection bias toward samples with more prominent coatings. From laboratory analyses, the thin, discontinuous bright coating that dominates the spectral signature of this unit and end-member is enriched in titanium dioxide with an underlying silica-enriched layer. Windows or optically thin areas of the Ti-rich coatings into the $\mathrm{Si}$-rich layer are presumably allow the $2.25 \mu \mathrm{m}$ absorption to be observed. The dark 1974 flow end-member spectrum is more typical of a relatively unaltered basaltic glass, with underdeveloped iron absorptions in the VNIR near 0.5 and $1.0 \mu \mathrm{m}$ (Figure 18). Subtle bands at 0.95, 1.15, and $2.25 \mu \mathrm{m}$ may be related to molecular water and opaline silica, but consistent with field observations, no spectral indication of the bright, Ti-rich coating is observed on this aa lava unit.

[37] The ash spectral end-member is characterized by VNIR features suggestive of poorly crystalline iron oxides influenced by olivine, pyroxene and glass, while the SWIR indicates the presence of opaline silica at $2.25 \mu \mathrm{m}$. The endmember spectrum exhibits overall reflectance values intermediate between the reflectance spectra of the aeolian ash and the ash crust samples illustrated in Figure 12, implying that the Ash spectral end-member likely contains a mixture of these two material types.

[38] The solfatara spectral end-member exhibits the highest overall reflectance values of all AVIRIS end-members (Figure 18). A sharp absorption edge at $0.45 \mu \mathrm{m}$ reflects the presence of native sulfur, clearly demonstrated by the sample spectra shown in Figure 16. Also evident in the solfatara endmember are small bands at 0.95 and $1.15 \mu \mathrm{m}$ resulting from molecular water and the prominent $2.25 \mu \mathrm{m}$ feature associated with opaline silica. The dominant interpretation of sulfur and opaline silica in the AVIRIS end-member is consistent with field observations of the whitish, silica-rich and yellowish, native sulfur-rich incrustations that dominate the surface. Spatial averaging with other materials, like windblown ash and lag deposits, altered basalt, and surrounding host rock, darkens the overall spectral signature of this end-member.

\subsection{End-Member Spatial Distribution}

[39] Distribution of the six AVIRIS end-members based on linear unmixing (see Appendix A) within the study area are illustrated in Figure 19. In general, the spatial distribution of end-members correlates well with mapped geologic surface units (Figure 3) and RMS error is low. Areas with higher RMS error correspond to the boundaries of units and regions to the northwest and southeast beyond the focus of this study that have greater amounts of vegetative ground cover. The linear unmixing model accounts for $99.4 \%$ of scene spectral variability.

[40] Distribution maps allow for comparison of spatial variation and mixing among spectral end-members as well as for correlation to geologic surface units. For instance, areas that exhibit relatively high model parameter values (abundances) for the older flows and ash spectral endmembers overlap in places, as do areas of high ash endmember abundance with the intermediate flows. This two-parameter overlap indicates a subpixel contribution from each material to the spectral signal, and the overlap is consistent with the observed superposition relationships between the mobile ash unit and both underlying older flows and the rough aa lavas of the intermediate flows. Ash abundance is also enhanced on the windward margin of the 1974 flow within the mantled subunit, verifying the presence and spectral influence of ash in this area. Figure 20 shows an RGB composite image composed of the older flows, ash, and dark 1974 flow end-members to qualitatively illustrate spatial variation and mixing among the AVIRIS end-members. 


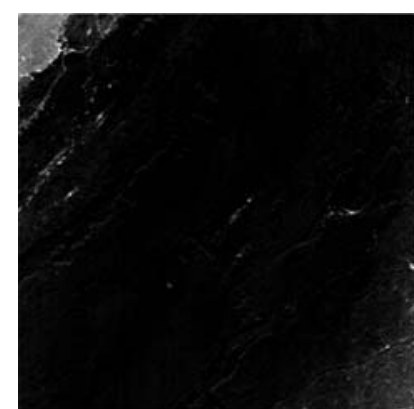

Solfatara

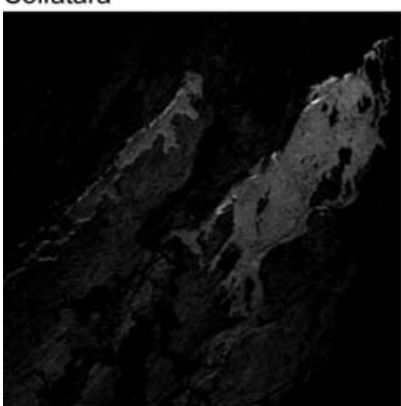

Bright 1974 Flow

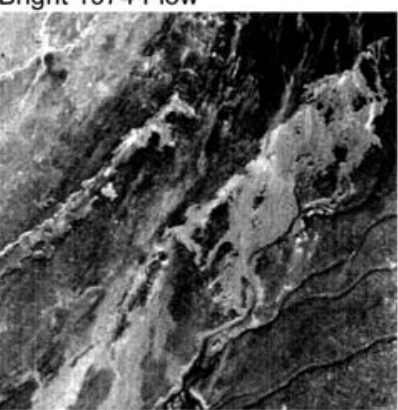

Intermediate Flows

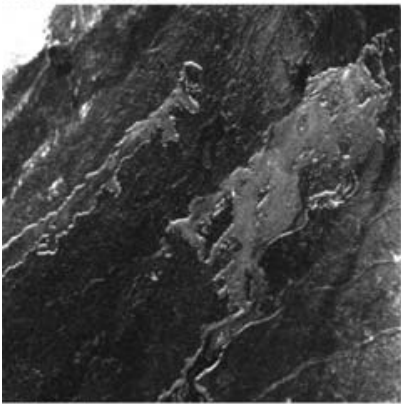

RMS Error

Figure 19. Spatial distribution of linear unmixing model parameters. Parameter images are each scaled linearly between 0 (dark) and 1 (bright) for comparison. RMS error (bottom) is scaled linearly from 0 (dark) to $0.4 \%$ (bright); the highest error is observed near the boundaries of units where mixing is most prevalent and in areas to the northwest and southeast beyond the focus of this study due to the presence of vegetation. (See Figure 2 for locations of AVIRIS end-member pixels.)

[41] Another spatial and spectral relationship identified is the spectral similarity between the 1974 and 1971 flows. The abundance map for the bright 1974 flow end-member correlates with areas of the 1971 flow inferred to exhibit the same bright surface coating, in particular along the fissure vent spatter ramparts where the flows originate. Downslope from the fissure vents, the abundance of the bright endmember diminishes, reflecting the observed decrease in coating thickness and coverage until the flows transition to dark aa lavas altogether. The dark 1974 flow spectral endmember also correlates to the dark subunit of the 1971 flow. Dark and bright spectra of the 1974 flow appear more extreme in overall albedo and spectral properties, probably because of the flow's slightly younger age.

[42] Last, the solfatara end-member abundance map shows moderately high values and a good correlation to the mapped solfatara geologic surface unit. Outlying areas that exhibit high solfatara model parameter values also exhibit high RMS errors, indicating that the spectral signature is not optimally modeled in those regions.

[43] The most diagnostic spectral feature of the solfatara is the $2.25 \mu \mathrm{m}$ signature of opaline silica. Because of the ubiquitous presence of opaline silica at the solfatara and in the Ka'u Desert in general, a band depth analysis (see Appendix A) was performed at the $2.25 \mu \mathrm{m}$ wavelength position. The resulting silica distribution map is presented in Figure 21. Highest values correspond to the silica-dominated surface incrustations at the solfatara, while lowest values correspond to the lower reaches of the dark 1974 flow subunit. A significant amount of silica is also evident in the

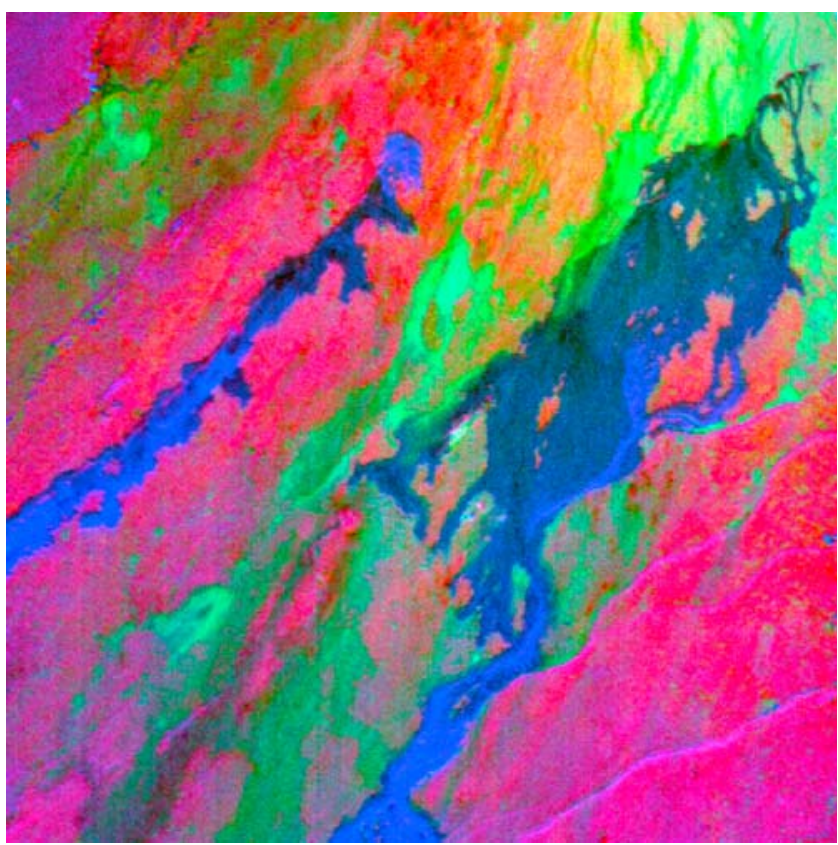

Figure 20. RGB composite image of linear unmixing model parameters older flows (red), ash (green), and the dark 1974 flow (blue), illustrating the subpixel mixing of Ka'u Desert materials. Notably, the older flows exhibits a gradation from yellow-orange in the north (due to a greater spatial contribution of ash materials) to purple in the south (suggesting increased similarity to the young, dark 1974 flow, or an overall decrease in albedo and surface coatings). The mantled portion of the 1974 flow also exhibits a green tone because of the spectral contribution of windblown ash. Individual RGB components are linearly stretched from 0 to 1 . 

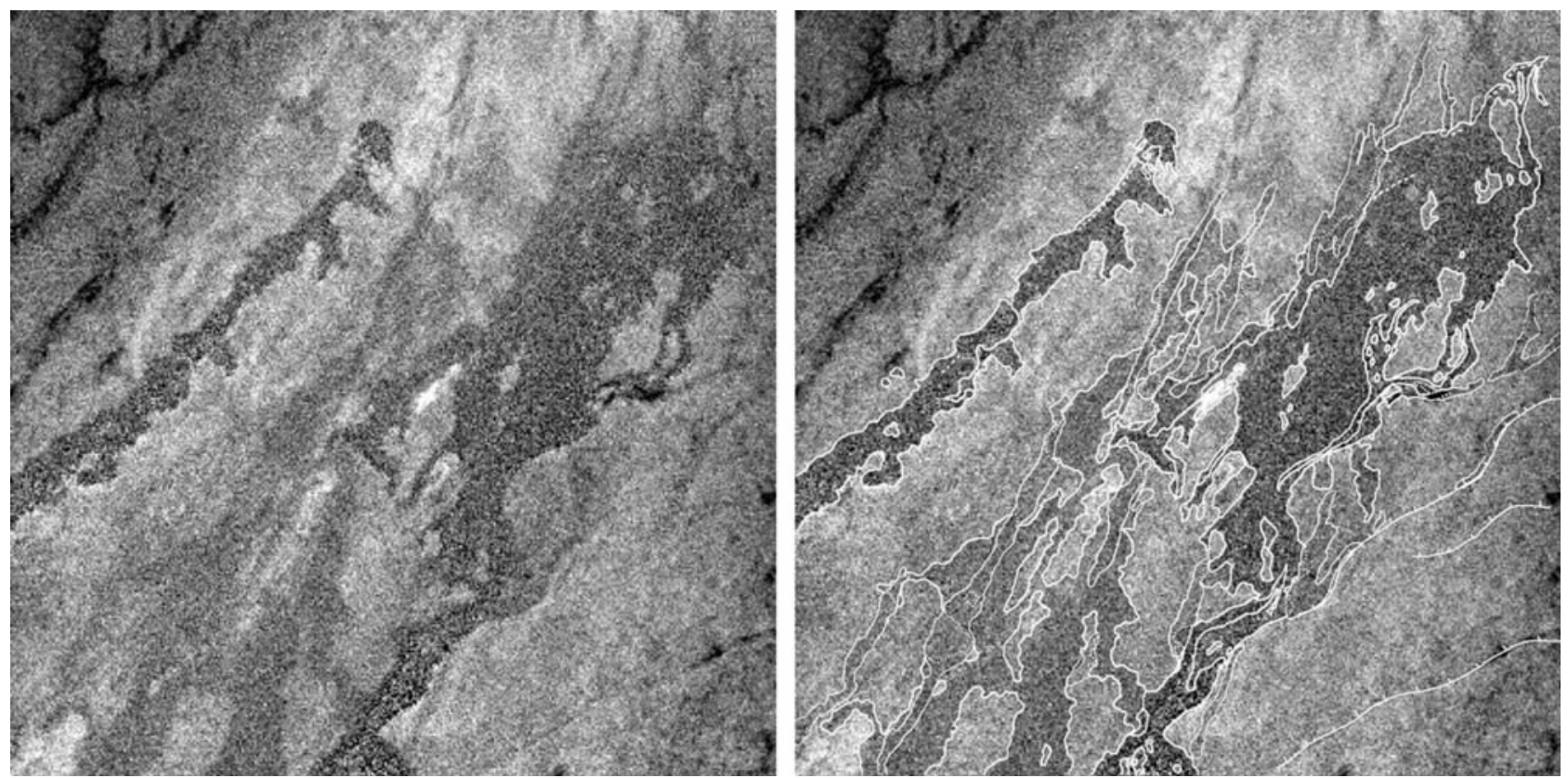

Figure 21. (left) Spatial distribution of opaline silica based on the AVIRIS band depth analysis at $2.25 \mu \mathrm{m}$. (right) The same but with outlines of mapped geologic surface units. Bright areas such as the solfatara correspond to high band depth values while dark areas are comparatively low in opaline silica. Image is linearly stretched from 0 to $8 \%$.

older flows unit and appears to be correlated with proximity to the Kilauea caldera. Pu'u Koa'e cinder cone, Cone Crater and Twin Pit crater (see Figures 1 and 2) also show an increased silica signature, which may indicate alteration associated with the emplacement of these landforms.

\section{Discussion}

\subsection{Spectral Variability}

[44] Although the materials in the Ka'u Desert are geologically young, we observe significant spectral variability and deviation from a simple basaltic signature. Coatings on both older and recent flows have distinct spectral properties; the bright Ti-rich coatings on the recent flows produce a unique reflectance spectrum with elevated values in the visible and negative slopes toward longer wavelengths. The older flows unit shows signs of developing poorly crystalline iron oxide and silica coatings consistent with observations made by Farr and Adams [1984] of coatings formed in other regions of Hawaii. The supply of detrital material from the Keanakako'i Ash formation and acidic weathering conditions may contribute to the enhanced development of coatings in the Ka'u Desert [e.g., Tosca et al., 2004; Schiffman et al., 2006].

[45] Aeolian and remnant layered ash deposits show evidence of both primary mafic mineralogy as well as insipient development of poorly crystalline iron oxides. Spectral signatures of silica in the ash unit are derived from surface crusts where ash grains are held together by silica cement. Windblown ash modifies the spectral characteristics of other materials in the Ka'u Desert as well, not only through subpixel mixing but also through the abrasive action of saltating grains. The bright Ti-rich coating of the 1974 flow is being removed in this way, and may represent the first stage in a weathering progression, after which breakdown of the glassy surface of the basalt leads to exposure of the vesicular subsurface and the development of coatings that resemble those of the older flows unit. Mobile ash also serves to alter the spectral properties of the intermediate flows unit by becoming trapped in the rough surfaces of the aa lavas.

[46] At the solfataras, hydrothermal activity modifies the basaltic substrate to produce both altered host rock (iron oxides) and surface deposits that are spectrally dominated by sulfur and hydrated silica. Silica incrustations are concentrated around vent openings in the downwind direction, making aerosol fallout a plausible formational mechanism. These leeward silica deposits at the solfatara may represent, on the small scale, a more widespread phenomenon of silica aerosol deposition downwind from Kilauea caldera. Alternatively, acidic rainfall or acid fog interaction, also ultimately due to Kilauean emissions, may induce in situ formation of silica through leaching and/or dissolution/ precipitation processes [Tosca et al., 2004; Schiffman et al., 2006; Minitti et al., 2007]. Either or both of these mechanisms could be responsible for the concentration of silica proximal to the caldera, which tapers with distance into the Ka'u Desert.

\subsection{Applicability to Mars}

[47] The ubiquitous presence of amorphous silica in nearly all Ka'u Desert materials has important planetary remote sensing implications and poses interesting questions regarding geochemical processes on Mars [e.g., McLennan, 2003]. Silica is present as coatings on recent and older flows, as a cementing agent in ash crusts, and as incrusta- 
tions at active solfatara sites. Whether produced through leaching and/or dissolution/precipitation in the arid, acidic regime in the Ka'u Desert or enhanced aerosol fallout from Kilauean vents, the presence of this hydrated amorphous silica is an indication of the interaction between crustal materials and water in such a manner that creates an alteration product with a distinct spectral signature that can be observed remotely. Moreover, the relatively minor amount of hydrated silica (in the form of coatings, etc.) that is required to produce the characteristic spectral signal makes understanding the geomorphic and geologic context of such detections on Mars even more important.

[48] Thus far, hydrated or opaline silica has been found in a wide variety of settings on Mars. On the plains adjacent to Valles Marineris (Ius, Melas, Candor, Ganges, and Juventae Chasmas), opaline silica is exposed in finely layered (meter scale) light-toned deposits and associated with Fe-sulfates as well as complex, sometimes inverted channel systems [Milliken et al., 2008; Bishop et al., 2009; Weitz et al., 2010]. In Noctis Labyrinthus, opaline silica deposits appear massive [Milliken et al., 2008], while at Mawrth Vallis, hydrated silica is interbedded with both $\mathrm{Al}$-bearing and $\mathrm{Fe} / \mathrm{Mg}$-bearing phyllosilicates [McKeown et al., 2009]. Hydrated silica or weakly altered basaltic glass exposures have also been identified in a number of southern highland craters [Milliken et al., 2008], and the Columbia Hills in Gusev crater host opaline silica deposits uncovered by MER Spirit [Ming et al., 2006; Squyres et al., 2008].

[49] This diversity of inferred geomorphic and geologic environments suggests that there have been multiple modes of silica formation on Mars and that these processes persisted for sufficient durations to produce the aerially and stratigraphically extensive deposits. A key consideration is whether these remote detections could result from micrometer-scale surface crusts and coatings that effectively mask the underlying bulk mineralogy, as is the case in the Ka'u Desert [see also Curtiss et al., 1985; Schiffman et al., 2006; Minitti et al., 2007]. Friable coatings like the bright, Ti-rich material may not survive over geologic time due to susceptibility to mechanical erosion, and the strong negative spectral slope that is characteristic of this coating has not been observed on Mars. However, silica is among the most physically and thermodynamically stable of terrestrial sedimentary minerals and has high preservation potential for biologic materials [Farmer and Des Marais, 1999]. In the ongoing search for new landing sites and possible sample return, it is therefore prudent to fully investigate areas with spectroscopic evidence of hydrated or opaline silica, especially in light of any geomorphic indication of aqueous activity.

\section{Conclusion}

[50] This study has demonstrated remote detection of amorphous silica and poorly crystalline iron oxides in a geologically young basaltic landscape. An increasing number of detections of opaline silica in a variety of settings on the Martian surface by CRISM [Bishop et al., 2008; Milliken et al., 2008; Bishop et al., 2009; McKeown et al., 2009; Weitz et al., 2010] and in the Columbia Hills by the MER Spirit rover [Ming et al., 2006; Squyres et al., 2008] may imply a wide range of formational mechanisms, including but not limited to hydrothermal activity, and environments conducive to the preservation of biologic systems. The Ka'u Desert is thus a uniquely applicable analog site that aids in spectral and geological interpretation of Martian landscapes as well as the identification of sites for future landed missions.

\section{Appendix A: AVIRIS Atmospheric Compensation and Hyperspectral Analysis}

[51] The three steps in reduction and analysis of AVIRIS hyperspectral data utilized in this study include (1) atmospheric correction and ground truth, (2) end-member selection and analysis, and (3) spatial reconstruction.

\section{A1. Atmospheric Correction and Ground Truth}

[52] The first step in processing the AVIRIS data set was to correct for the scattering and absorption effects of aerosols and gases in the atmosphere. This correction was performed with the MODTRAN4-based procedure, ACORN (Atmospheric Correction Now) [Chandrasekhar, 1960; ImSpec, 2001]. The program utilizes a radiative transfer model to convert spectrally and radiometrically calibrated hyperspectral radiance data to apparent ground reflectance (radiance coefficient) values taking into account certain user-supplied parameters such as latitude, longitude, time and date of acquisition, average terrain elevation, estimated visibility, and a climate model. The radiative transfer model is based on the equation:

$$
L_{t(\lambda)}=\frac{1}{\pi}\left[F_{o(\lambda)} \rho_{a(\lambda)}+\frac{F_{o(\lambda)} T_{d(\lambda)} T_{u(\lambda)} \rho_{(\lambda)}}{\left(1-s_{(\lambda)} \rho_{(\lambda)}\right)}\right]
$$

where $L_{t}$ is the total radiance on sensor, $F_{o}$ is the solar irradiance at the top of the atmosphere, $T_{d}$ is the downward transmittance of the atmosphere, $T_{u}$ is the upward transmittance of the atmosphere, $\rho$ is the spectral reflectance of the surface, $\rho_{a}$ is the reflectance of the atmosphere, $s$ is the albedo of the atmosphere above the surface, and $\lambda$ is wavelength [Green et al., 1996; ImSpec, 2001]. ACORN accounts for appropriate types and abundances of atmospheric gases in its estimation of the atmospheric component of the radiance spectra, but does not take into account any additional aerosols that might be present in a volcanic plume.

[53] A "polishing" algorithm was subsequently applied to the atmospherically corrected spectra. The Empirical Flat Field Optimal Reflectance Transformation (EFFORT) attempts to remove artifacts in the data set induced during the calibration or atmospheric correction procedures, effectively smoothing the spectra [Boardman, 1998]. EFFORT is an adjustment that attempts to identify a gain near unity and offset near zero for all channels that improves the overall ability of the data to be confidently compared with library spectra. Due to inherently different absorption behaviors in different wavelength regions, the user can select multiple polynomial orders each applied to a designated wavelength segment. The orders chosen are a result of trial and error analysis to balance smoothing effects against loss of detailed spectral information.

[54] Ground truth spectral measurements obtained in three albedo regions (relatively high, intermediate, and relatively low) within the study area (Figure 2) were used to assess the quality of the atmospheric correction. In these three areas, 


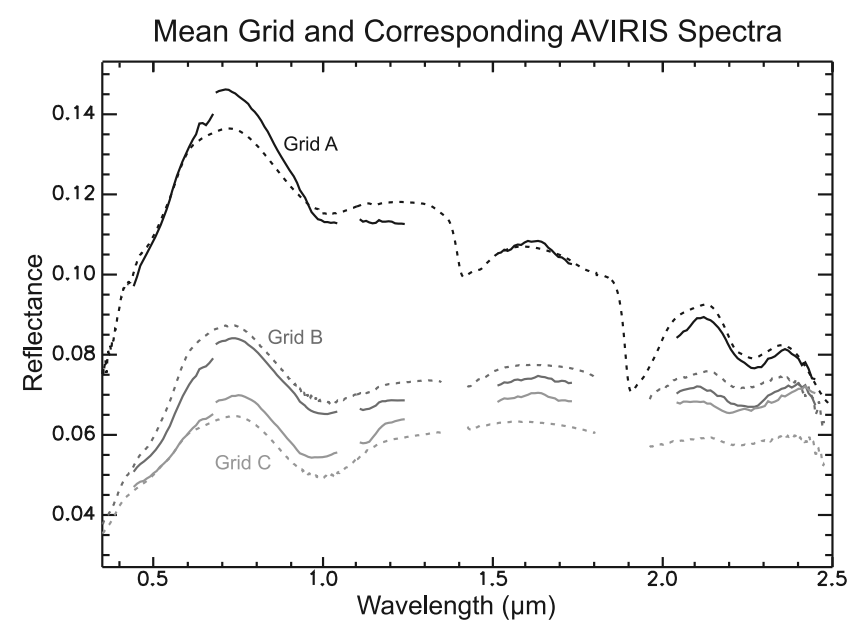

Figure A1. Averaged field reflectance spectra (dotted lines) and colocated AVIRIS spectra (solid lines) for three albedo regions (grid sites) in the study area: relatively high (grid A), intermediate (grid B) and relatively low (grid C). Locations of grid sites are indicated in Figure 2.

spectral measurements are acquired in $5 \mathrm{~m}$ increments within a 50 by $50 \mathrm{~m}$ grid using a portable Analytical Spectral Device (ASD) visible and near infrared spectrometer. For each grid, the resulting 111 spectra are averaged together to produce a single spectrum that is compared to the collocated AVIRIS pixel (Figure A1). Good correlation in overall reflectance values as well as with individual absorption features between each pair serves to verify the atmospheric correction and smoothing algorithm results.

\section{A2. End-Member Selection and Analysis}

[55] Hyperspectral analysis of atmospherically corrected and field verified AVIRIS data involved a series of processing steps aimed at identifying and interpreting spectrally unique pixels in the study area. These steps consisted of applying the Minimum Noise Fraction (MNF), Pixel Purity Index (PPI), N-Dimensional Visualizer (NDV), and endmember selection routines that are part of the Interactive Development Language (IDL) Environment for Visualizing Images (ENVI) software package. Once spectral endmembers were identified through this process, mineralogy was inferred through examination and comparison with library mineral spectra.

[56] 1. The Minimum Noise Fraction (MNF) transformation recognizes noise in the data as estimated from the covariance matrix, and then applies a standard principal component analysis to the decorrelated noise. The result is an MNF image cube in which bands are ranked by order of decreasing variance. For example, MNF band 1 has the highest eigenvalue and therefore contains the greatest variance in the scene. By limiting further analysis to only the MNF bands that display spatially coherent variation, noise is decreased and the number of dimensions in the data set is reduced.

[57] 2. The Pixel Purity Index (PPI) calculation iteratively projects n-dimensional scatterplots (where " $n$ " is the selected number of MNF bands) onto a random unit vector, taking note of the extreme pixels in each projection [Boardman et al., 1995]. The total number of times that each pixel is considered extreme is used to create a DN image of spectral purity. Thirty thousand iterations of the PPI calculation were performed in this study.

[58] 3. The N-Dimensional Visualizer tool is used to interactively view the purest pixels in $n$-dimensional space and cluster those pixels that form the extreme endpoints of data clouds. All spectra corresponding to the pixels from one cluster (usually 5-10 pixels) are averaged to produce one potential end-member spectrum. Figure 2 and Figure 18 show the locations of selected end-member pixels in the study area. Each potential end-member spectrum is further scrutinized for individuality before it is included in the final end-member set (Figure 18).

[59] 4. Mineralogic interpretation of the end-member spectra is based on absorption features present in the spectral regions from approximately 0.425 to $1.25 \mu \mathrm{m}$ (termed VNIR for visible and near infrared) and 2.05-2.45 $\mu \mathrm{m}$ (short wavelength infrared, or SWIR). The overall spectral shape (slope, wavelength of maximum reflectance) was also examined. Observed absorption features in both the VNIR and SWIR regions of the end-member spectra were compared to published laboratory spectra, namely the USGS spectral library, in order to infer mineralogic components. The USGS spectral library complied by Clark et al. [1993] contains absolute reflectance spectra of 423 minerals in the wavelength range of $0.2-3.0 \mu \mathrm{m}$. The library was rescaled to AVIRIS spectral resolution for comparison to the endmember spectra. Features in the VNIR and SWIR were enhanced by removing the continuum, a technique in which a particular spectrum is divided by a low-order polynomial function fitted to the spectrum at wavelengths outside of the absorption features of interest.

\section{A3. Spatial Reconstruction}

[60] Understanding the spatial distribution of materials with similar spectral characteristics to the selected endmembers is aided by the use of linear unmixing and band depth calculations. Linear unmixing is a simple approach that attempts to model each pixel in the scene as a linear combination of the end-member spectra. In this case, the entire AVIRIS spectral range $(0.4$ to $2.5 \mu \mathrm{m}$, excepting atmospheric absorption bands) was utilized. The end result of this technique is a series of maps covering the study area that illustrate the distribution of each end-member component as well as the RMS errors associated with the model fits.

[61] Band depth calculations are performed on a specific wavelength range that spans a given diagnostic spectral feature in order to isolate and quantify the magnitude of the absorption. The band depth calculation employed in this study takes the form of

$$
1-\left[\mathrm{R}_{\mathrm{C}} /\left(\mathrm{a}^{*} \mathrm{R}_{\mathrm{S}}-\mathrm{b}^{*} \mathrm{R}_{\mathrm{L}}\right)\right]
$$

where $R_{C}$ is the reflectance at the center wavelength of the absorption feature $\left(\lambda_{\mathrm{C}}\right), \mathrm{R}_{\mathrm{S}}$ is the reflectance at the short wavelength side of the feature $\left(\lambda_{S}\right), R_{L}$ is the reflectance at 
the long wavelength side of the feature $\left(\lambda_{\mathrm{L}}\right), \mathrm{a}=1-\mathrm{b}$, and $\mathrm{b}=$ $\left(\lambda_{\mathrm{C}}-\lambda_{\mathrm{S}}\right) /\left(\lambda_{\mathrm{L}}-\lambda_{\mathrm{S}}\right)$ [see also Pelkey et al., 2007]. Band depth may then be displayed to show spatial variability with respect to surface features within the study area.

[62] Acknowledgments. We are grateful to Alian Wang for her expertise and use of the Raman spectroscopy lab at Washington University. This work benefited from constructive review from Janice Bishop and an anonymous reviewer. Support provided by the NASA Planetary Geology and Geophysics Program by a grant to Washington University and the NASA Mars Reconnaissance Orbiter project.

\section{References}

Anderson, J. H., Jr., and K. A. Wickersheim (1964), Near infrared characterization of water and hydroxyl groups on silica surfaces, Surf. Sci., 2 , 242-260, doi:10.1016/0039-6028(64)90064-0.

Arvidson, R. E., F. P. Seelos, K. S. Deal, W. C. Koeppen, N. O. Snider, J. M Kieniewicz, B. M. Hynek, M. T. Mellon, and J. B. Garvin (2003), Mantled and exhumed terrains in Terra Meridiani, Mars, J. Geophys. Res., 108 (E12), 8073, doi:10.1029/2002JE001982.

Arvidson, R. E., et al. (2005), Spectral reflectance and morphologic correlations in eastern Terra Meridiani, Mars, Science, 307, 1591-1594, doi:10.1126/science. 1109509 .

Arvidson, R. E., et al. (2008), Spirit Mars Rover Mission to the Columbia Hills, Gusev Crater: Mission Overview and selected results from the Cumberland Ridge to Home Plate, J. Geophys. Res., 113, E12S33, doi:10.1029/2008JE003183.

Bandfield, J. L., V. E. Hamilton, and P. R. Christensen (2000), A global view of Martian surface compositions for MGS-TES, Science, 287, 1626-1630, doi:10.1126/science.287.5458.1626.

Bibring, J.-P., et al. (2004), OMEGA: Observatiore pour la Minéralogie, l'Eau, les Glaces et l'Activité, in Mars Express: The Scientific Payload, edited by A. Wilson, pp. 37-49, Eur. Space Agency, Noordwijk, Netherlands.

Bibring, J.-P., et al. (2005), Mars surface diversity as revealed by the OMEGA/Mars Express observations, Science, 307, 1576-1581, doi:10.1126/ science.1108806.

Bishop, J. L., H. Froschl, and R. L. Mancinelli (1998), Alteration processes in volcanic soils and identification of exobiologically important weathering products on Mars using remote sensing, J. Geophys. Res., 103(E13), 31,457-31,476, doi:10.1029/1998JE900008.

Bishop, J. L., M. E. Minitti, M. D. Lane, and C. M. Weitz (2003), The influence of glassy coatings on volcanic rocks from Mauna Iki, Hawaii, and applications to rocks on Mars, Lunar Planet. Sci., XXXIV, Abstract 1516.

Bishop, J. L., et al. (2008), Phyllosilicate diversity and past aqueous activity revealed at Mawrth Vallis, Mars, Science, 321, 830-833, doi:10.1126/ science. 1159699.

Bishop, J. L., et al. (2009), Mineralogy of Juventae Chasma: Sulfates in the light-toned mounds, mafic minerals in the bedrock, and hydrated silica and hydroxylated ferric sulfate on the plateau, J. Geophys. Res., 114 E00D09, doi:10.1029/2009JE003352.

Boardman, J. W. (1998), Post-ATREM polishing of AVIRIS apparent reflectance data using EFFORT: A lesson in accuracy versus precision, in Proceedings of the 8th Annual Airborne Earth Science Workshop, JPL Publ. 99-17, p. 53.

Boardman, J. W., F. A. Kruse, and R. O. Green (1995), Mapping target signatures via partial unmixing of AVIRIS data, in Proceedings of the 5th Annual Airborne Earth Science Workshop, JPL Publ. 95-1, 23-26.

Casadevall, T. J., and R. W. Hazlett (1983), Thermal areas on Kilauea and Mauna Loa volcanoes, Hawaii, J. Volcanol. Geotherm. Res., 16, 173188, doi:10.1016/0377-0273(83)90028-8.

Chandrasekhar, S. (1960), Radiative Transfer, Dover, New York.

Chemtob, S. M., B. L. Jolliff, and R. E. Arvidson (2006), Si- and Ti-rich surface coatings on Hawaiian basalt and implications for remote sensing on Mars, Lunar Planet. Sci., XXXVII, Abstract 1443.

Chemtob, S. M., G. R. Rossman, J. M. Eiler, and B. L. Jolliff (2009), Silica coatings on the 1974 Kilauea flow: New SEM and SIMS results and implications for Mars, Lunar Planet. Sci., XL, Abstract 2156.

Christensen, P. R., et al. (2000), Detection of crystaline hematite mineralization on Mars by the Thermal Emission Spectrometer: Evidence for near-surface water, J. Geophys. Res., 105(E4), 9623-9642, doi:10.1029/1999JE001093.

Clark, R. N., G. A. Swayze, A. J. Gallagher, T. V. V. King, and W. M. Calvin (1993), The U. S. Geological Survey, Digital Spectral Library: Version 1 : 0.2 to 3.0 microns, U.S. Geol. Surv. Open File Rep. 93-592, 1340 p.
Craddock, R. A., R. P. Irwin III, R. Williams, D. A. Swanson, A. D. Howard, C. Quantin, and D. R. Zimbelman (2006), Topical Martain field studies in the Ka'u Desert, Hawaii, Lunar Planet. Sci., XXXVII, Abstract 1384.

Curtiss, B., J. B. Adams, and M. S. Ghiorso (1985), Origin, development and chemistry of silica-alumina rock coatings from the semi-arid regions of the island of Hawaii, Geochim. Cosmochim. Acta, 49, 49-56, doi:10.1016/0016-7037(85)90190-5.

Easton, R. M. (1987), Stratigraphy of Kilauea Volcano, in Volcanism in Hawaii, edited by R. W. Decker et al., U.S. Geol. Surv. Prof. Pap., 1350, 243-260.

Farmer, J. D., and D. J. Des Marais (1999), Exploring for a record of ancient Martian life, J. Geophys. Res., 104(E11), 26,977-26,995, doi:10.1029/ 1998JE000540.

Farr, T. G., and J. B. Adams (1984), Rock coatings in Hawaii, Geol. Soc. Am. Bull., 95, 1077-1083, doi:10.1130/0016-7606(1984)95<1077. $\mathrm{RCIH}>2.0 . \mathrm{CO} ; 2$.

Gendrin, A., et al. (2005), Sulfates in Martian layered terrains: The OMEGA/Mars Express view, Science, 307, 1587-1591, doi:10.1126/ science. 1109087

Giambelluca, T., and M. Sanderson (1993), The water balance and climate classification, in Prevailing Trade Winds: Weather and Climate in Hawai'i, edited by M. Sanderson, pp. 56-72, Univ. of Hawaii Press, Honolulu.

Glaze, L. S., G. N. Karas, S. I. Chernobieff, M. W. Thomas, E. D. Paylor, and D. C. Pieri (1992), Kilauea: Compiled Volcanology Data, Set 1, Jet Propul. Lab., Calif. Inst. of Technol., Pasadena.

Golden, D. C., S. R. Yang, R. V. Morris, H. V. Lauer Jr., and D. W. Ming (1993), Mineralogy of three slighly palagonized basalitic tephra samples from the summit of Mauna Kea, Hawaii, J. Geophys. Res., 98(E2), 34013411, doi:10.1029/92JE02590.

Green, R. O., D. A. Roberts, and J. E. Conel (1996), Characterization and compensation of the atmosphere for the inversion of AVIRIS calibrated radiance to apparent surface reflectance, $J P L P u b l$. 96-4, 135-146.

Green, R. O., et al. (1998), Imaging spectroscopy and the Airborne Visible/ Near Infrared Imaging Spectrometer (AVIRIS), Remote Sens. Environ., 65(3), 227-248, doi:10.1016/S0034-4257(98)00064-9.

Guinness, E. A., R. E. Arvidson, B. L. Jolliff, K. D. Seelos, F. P. Seelos, D. W. Ming, R. V. Morris, and T. G. Graff (2007), Hyperspectral reflectance mapping of cinder cones at the summit of Mauna Kea and implications for equivalent observations on Mars, J. Geophys. Res., 112, E08S11, doi:10.1029/2006JE002822.

Hamilton, V. E., R. V. Morris, J. E. Gruener, and S. A. Mertzman (2008), Visible, near-infrared, and middle infrared spectroscopy of altered basaltic tephras: Spectral signatures of phyllosilicates, sulfates, and other aqueous alteration products with application to the mineralogy of the Columbia Hills of Gusev Crater, Mars, J. Geophys. Res., 113 , E12S43, doi:10.1029/2007JE003049.

Holcomb, R. T. (1987), Eruptive history and long-term behavior of Kilauea Volcano, in Volcanism in Hawaii, edited by R. W. Decker et al., U.S. Geol. Surv. Prof. Pap., 1350, 261-350.

Hunt, G. R., J. W. Salisbury, and C. J. Lenhoff (1973), Visible and nearinfrared spectra of minerals and rocks: VI. Additional silicates, Mod. Geol., 4, 85-106.

Hynek, B. M., R. E. Arvidson, and R. J. Phillips (2002), Geologic setting and origin of Terra Meridiani hematite deposit on Mars, J. Geophys. Res. 107(E10), 5088, doi:10.1029/2002JE001891.

ImSpec (2001), ACORN Version 4.0 User's Guide, Boulder, Colo.

Kuebler, K., A. Wang, J. J. Freeman, and B. L. Jolliff (2006), Database of Raman mineral spectra for planetary surface exploration, Lunar Planet. Sci., XXXVII, Abstract 1907

Malin, M. C., D. Dzurisin, and R. P. Sharp (1983), Stripping of Keanakakoi tephra on Kilauea Volcano, Hawaii, Geol. Soc. Am. Bull., 94, 1148 1158, doi:10.1130/0016-7606(1983)94<1148:SOKTOK>2.0.CO;2.

McKeown, N. K., J. L. Bishop, E. Z. Noe Dobrea, M. Parente, B. L. Ehlmann, J. F. Mustard, S. L. Murchie, J.-P. Bibring, and E. Silver (2009), Characterization of phyllosilicates observed in the central Mawrth Vallis region, Mars, their potential formational processes, and implications for past climate, J. Geophys. Res., 114, E00D10, doi:10.1029/2008JE003301.

McLennan, S. M. (2003), Sedimentary silica on Mars, Geology, 31, 315318, doi:10.1130/0091-7613(2003)031<0315:SSOM > 2.0.CO;2.

Milliken, R. E., et al. (2008), Opaline silica in young deposits on Mars, Geology, 36, 847-850, doi:10.1130/G24967A.1.

Ming, D. W., et al. (2006), Geochemical and mineralogical indicators for aqueous processes in the Columbia Hills of Gusev crater, Mars, J. Geophys. Res., 111, E02S12, doi:10.1029/2005JE002560.

Minitti, M. E., C. M. Weitz, M. D. Lane, and J. L. Bishop (2007), Morphology, chemistry, and spectral properties of Hawaiian rock coatings and 
implications for Mars, J. Geophys. Res., 112, E05015, doi:10.1029/ 2006JE002839.

Morris, R. V., H. V. Lauer Jr., C. A. Lawson, E. K. Gibson Jr., G. A. Nace, and C. Stewart (1985), Spectral and other physicochemical properties of submicron powders of Hematite $\left(\alpha-\mathrm{Fe}_{2} 0_{3}\right)$, Maghemite $\left(\gamma-\mathrm{Fe}_{2} \mathrm{O}_{3}\right)$, Magnetite $\left(\mathrm{Fe}_{3} \mathrm{O}_{4}\right)$, Goethite $(\alpha-\mathrm{FeOOH})$, and Lepidocrocite $(\gamma-\mathrm{FeOOH})$, J. Geophys. Res., 90(B4), 3126-3144, doi:10.1029/JB090iB04p03126.

Murchie, S., et al. (2007), Compact Reconnaissance Imaging Spectrometer for Mars (CRISM) on Mars Reconnaissance Orbiter (MRO), J. Geophys. Res., 112, E05S03, doi:10.1029/2006JE002682.

Naughton, J. J., V. A. Greenberg, and R. Goguel (1976), Incrustations and funarolic condesates at Kilaeua Volcano, Hawaii: Field, drill-hole and laboratory observations, J. Volcanol. Geotherm. Res., 1, 149-165, doi:10.1016/0377-0273(76)90004-4

Pelkey, S. M., et al. (2007), CRISM multispectral summary products: Parameterizing mineral diversity on Mars from reflectance, J. Geophys. Res., 112, E08S14, doi:10.1029/2006JE002831.

Pieters, C. M., and P. A. J. Englert (1993), Remote Geochemical Analysis: Elemental and Mineralogical Composition, Topics in Remote Sens. vol. 4, 594 pp., Cambridge Univ. Press, Cambridge, U. K.

Poulet, F., J.-P. Bibring, J. F. Mustard, A. Gendrin, N. Mangold, Y. Langevin, R. E. Arvidson, B. Gondet, C. Gomez, and the Omega Team (2005), Phyllosilicates on Mars and implications for early Martian climate, Nature, 438, 623-627, doi:10.1038/nature04274.

Schiffman, P., H. J. Spero, R. J. Southard, and D. A. Swanson (2000), Controls on palagonitization versus pedogenic weathering of basaltic tephra: Evidence from the consolidation and geochemistry of the Keanakako' Ash Member, Kilauea Volcano, Geochem. Geophys. Geosyst., 1(8), 1040, doi:10.1029/2000GC000068.

Schiffman, P., R. Zierenberg, N. Marks, J. Bishop, and M. D. Dyar (2006), Acid-fog deposition at Kilauea Volcano: A possible mechanism for the formation of siliceous-sulfate rock coatings on Mars, Geology, 34, 921-924, doi:10.1130/G22620A.1.

Sherman, G. D., and G. Uehara (1956), The weathering of olivine basalt in Hawaii and its pedogenic significance, Soil Sci. Soc. Am., 20, 337-340.

Siegel, B. Z., M. Nachbar-Hapai, and S. M. Siegel (1990), The contribution of sulfate to rainfall $\mathrm{pH}$ around Kilauea Volcano, Hawaii, Water Air Soil Pollut., 52(3-4), 227-235, doi:10.1007/BF00229435.

Squyres, S. W., et al. (2004), The Opportunity Rover's Athena Science Investigation at Meridiani Planum, Mars, Science, 306, 1698-1703, doi:10.1126/science.1106171.

Squyres, S. W., et al. (2008), Discovery of silica-rich deposits on Mars by the Spirit Rover, Science, 320, 1063-1067, doi:10.1126/science.1155429.
Swanson, D. A., and R. L. Christensen (1973), Tragic base surge in 1970 at Kilauea Volcano, Geology, 1, 83-86, doi:10.1130/0091-7613(1973) $1<83$ :TBSIAK $>2.0 . \mathrm{CO} ; 2$

Swayze, G. A., R. N. Clark, S. J. Sutley, C. A. Gent, B. W. Rockwell, D. L. Blaney, J. L. Post, and B. P. Farm (2003), Mineral mapping Mauna Kea and Mauna Loa shield volcanoes on Hawaii using AVIRIS data and the USGS Tetracorder Spectral Identification System: Lessons applicable to the search for relict Martian hydrothermal systems, in Proceedings of the 11th JPL Airborne Earth Science Workshop, JPL Publ., 03-4, 373-387.

Tosca, N. J., S. M. McLennan, D. H. Lindsley, and M. A. A. Schoonen (2004), Acid-sulfate weathering of synthetic Martian basalt: The acid fog model revisited, J. Geophys. Res., 109, E05003, doi:10.1029/ 2003JE002218.

Vane, G., E. G. Hansen, W. M. Parter, R. O. Green, T. G. Chrien, and H. T. Enmark (1993), The airborne visible/near infrared imaging spectrometer (AVIRIS), Remote Sens. Environ., 44(2-3), 127-143, doi:10.1016/00344257(93)90012-M.

Weitz, C. M., R. E. Milliken, J. A. Grant, A. S. McEwen, R. M. E. Williams, J. L. Bishop, and B. J. Thomson (2010), Mars Reconnaissance Orbiter observations of light-toned layered deposits and associated fluvial landforms on the plateaus adjacent to Valles Marineris, Icarus, 205, 73102, doi:10.1016/j.icarus.2009.04.017.

White, A. F., and M. F. Hochella Jr. (1992), Surface chemistry associated with the cooling and subaerial weathering of recent basalt flows, Geochim. Cosmochim. Acta, 56, 3711-3721, doi:10.1016/0016-7037(92)90164-E.

Wolfe, E. W., and J. Morris (1996), Geologic map of the island of Hawaii, U.S. Geol. Surv. Geol. Invest. Ser. Map, I-2524-A, scale 1:100000.

Wright, T. L. (1971), Chemistry of Kilauea and Mauna Loa lava in space and time, U.S. Geol. Surv. Prof. Pap., 735.

R. E. Arvidson and B. L. Jolliff, Department of Earth and Planetary Sciences, Washington University in Saint Louis, Saint Louis, MO 63130, USA.

S. M. Chemtob, Department of Geological and Planetary Sciences, California Institute of Technology, Pasadena, CA 91225, USA.

D. W. Ming and R. V. Morris, ARES, NASA Johnson Space Center, Houston, TX 77058, USA.

K. D. Seelos, Johns Hopkins University Applied Physics Laboratory, Laurel, MD 20723, USA.

G. A. Swayze, U.S. Geological Survey, Denver, CO 80225, USA. 